\title{
Does Service Bundling Reduce Churn?
}

\author{
Jeffrey Prince and Shane Greenstein*
}

November 2011

\begin{abstract}
We examine whether bundling in telecommunications services reduces churn using a series of large, independent cross sections of household decisions. To identify the effect of bundling, we construct a pseudo-panel dataset and utilize a linear, dynamic panel-data model, supplemented by nearest-neighbor matching. We find bundling does reduce churn for all three "triple-play" services. However, the effect is only "visible" during times of turbulent demand. We also find evidence that broadband was substituting for pay television in 2009. This analysis highlights that bundling helps with customer retention in service industries, and may play an important role in preserving contracting markets.
\end{abstract}

\footnotetext{
* Indiana University, Department of Business Economics and Public Policy, Kelley School of Business, and Northwestern University, Department of Management and Strategy, Kellogg School of Management. We thank Greg Rosston, Avi Goldfarb, Scott Savage, as well as many seminar participants for many useful comments. We thank Time-Warner Cable for funding through the Time Warner Research Program on Digital Communications. We also thank Forrester Research for its cooperation in providing data through a site license to the Kellogg School of Management. We are responsible for all remaining errors.
} 


\section{Introduction}

A firm engages in bundling when it sells two or more separate products in a package for a single price. Bundling is pervasive in many markets. In this paper we study bundling of wired telephone, cable television, and broadband Internet services by cable operators, often called "triple play." Virtually every major cable television firm in the United States offers triple play, and many households subscribe to it.

The way in which cable firms offer triple-play bundling is different from other examples that have been studied. In particular, cable firms offer services, not products. The recurring nature of services allows bundling to play two distinct roles - either to attract new users to a firm's service, or to prevent existing users from leaving. In a one-time purchase of bundled services, such as a movie, there is no reason to distinguish between these two roles, as the latter role is irrelevant. In cable services, however, users may go years with the same supplier before reconsidering their arrangement. It is quite natural to focus on the importance of bundling for delaying those moments of reconsideration, which can result in a buyer changing suppliers. That motivates this paper's key question: does bundling reduce churn, and if so, how much?

More specifically, this study examines whether bundles reduced churn for cable services between 2007 and 2009, when offering triple play became pervasive at virtually every cable firm in the United States. We define churn as the abandonment of a service or service provider by an existing user, a household. In this study, we reasoned that if bundling reduces churn, then it causes households to be less likely to switch services (and/or service providers) once they have purchased a bundle. We measured churn for wired telephone, pay television (cable or satellite), and broadband Internet, as well as provision of these services by cable companies, employing a rich consumer marketing dataset provided by Forrester Research.

A recent survey by the Federal Communications Commission (FCC) provides suggestive evidence of this role of bundling, as nearly 40 percent of respondents noted that having to change their bundle was a major reason for keeping their broadband service. That survey's statistics indicate one of the key issues we confront: bundling may reduce churn by altering the cost of switching (i.e., state dependence). Such switching costs are far less explicit (and perhaps even less deliberate) than those created by customers signing a contract (e.g., as with many cell phoneservice providers). Instead, these costs may come in the form of the displeasure and/or 
inconvenience experienced by bundling households upon switching a service, as they must restructure their entire telecommunications service portfolio by dismantling their bundle.

Beyond the FCC study, a long-standing debate about the effects of bundling motivates our analysis. Some would argue that bundling generates “stickiness," which potentially reflects consumer preferences and benefits producers by reducing the frequency of switching. Others would argue that bundling creates switching costs, which enhances firms' market power and ultimately comes at the expense of consumer welfare. While each side essentially takes bundling's causal effect on churn as a fact, to our knowledge there is no empirical evidence about bundling's effect and its magnitude in this respect. In addition to providing evidence of bundling's effect, our paper contributes to this debate by disentangling bundling's casual effect from other factors spuriously correlated with churn.

In addition to any effect on churn, bundling may also screen inert consumers (unobserved heterogeneity), identifying consumers who are inherently least likely to switch to another supplier. If this is occurring, bundling does not cause churn reduction, but rather identifies households less likely to churn. This is a key issue for our empirical analysis, which examines a much larger and richer dataset than the FCC survey.

The data for this study come from Forrester and consist of tens of thousands of surveys of American households. Though rich in detail about users, the data are not a panel of the same households, but only a series of independent, repeated cross sections. This makes it impossible for us to observe the state (e.g., bundle status in 2007) and choice (e.g., broadband service in 2008) for the same household, which is how most common theories are framed. To overcome this limitation, we build a pseudo (or synthetic) panel and utilize a linear, dynamic-panel data model, following known econometric techniques, e.g., Moffitt (1993) and Verbeek and Vella (2005). We supplement these methods on some occasions, employing nearest-neighbor matching methods described in Abadie et al. (2004). Our general approach is novel for the literature on bundling, and, to our knowledge, the latter extension is also novel in the econometric literature. Most of the existing literature on bundling is theoretical, and addresses a wide array of potential competitive issues when users face switching costs (e.g., Farrell and Klemperer, 2007). This paper focuses on empirically examining one of the key premises and implicit predictions of most models - that bundling creates switching costs for users and switching costs reduce churn. This 
prediction is quite pervasive in the literature. It arises in models where users are forward looking and demand price discounts, or where they are not and find themselves facing an unexpected cost when they attempt to switch suppliers.

Prior literature has established several reasons why firms may wish to bundle, which have clear links to churn reduction. Many papers examined the use of bundling as a means to leverage market power. This may occur through exclusionary practices (Whinston, 1990) or reduction of competition through differentiation (Carbajo et al., 1990; Chen, 1997). Prior work has also examined bundling as a means to (second degree) price discriminate. Specifically, bundling can be used to reduce heterogeneity in consumers' valuations, allowing a firm with market power to extract more surplus from consumers (Adams and Yellen, 1976; Schmalensee, 1982; McAfee et al., 1989; Stole, 2003; Crawford, 2008). This has clear detrimental effects on consumer welfare when it involves consumers purchasing products of little or no interest to them (Bakos and Brynjolfsson, 1999; Armstrong, 1996). ${ }^{1}$ The welfare effects are close to neutral, however, if users anticipate the later surplus reduction, and receive advanced discounts at the moment they sign up for the bundle (Shapiro and Varian, 1999; Farrell and Klemperer, 2007).

These explanations overlap with some of the behavior we observe. For example, discounting for new users is common in this industry. However, we have reason to believe that many common explanations, such as those linked to exploiting market power, may not explain bundling motivations for the firms we study. During our period of study, cable firms were engaged in mixed bundling, which allows consumers to make a la carte purchases. Offering such bundles would severely hamper or nullify attempts to price discriminate or leverage market power via bundle offerings.

If triple-play bundling does reduce churn, communications and broadcasting markets could be impacted in several ways. First, as noted above, it could enhance market power both in the short and long run. In the short run, consumers' lessened willingness to switch would allow firms to sustain higher prices, ceteris paribus, but forward-looking consumers demanding discounts up front may mitigate this effect. In the long run, increased switching costs may help

\footnotetext{
${ }^{1}$ The literature provides several other motivations for firms to bundle. A non-exhaustive list includes entry deterrence (Nalebuff, 1999); dynamic gains through increased R\&D incentives (Choi, 1998); cost savings (Salinger, 1995); or realizing economies of scope (Gandal et al., 2011). Our study differs significantly from these explanations.
} 
deter entry, as potential competitors would find luring new customers away from their current service provider more difficult. In addition, it could help prevent important markets from contracting. Specifically, our data highlight recent contractions in both the wired telephone and pay-television markets. Triple-play bundles may offer a way for cable firms, and other firms capable of offering a telecommunications bundle, to try to preserve the size of these markets.

We found that bundling does reduce churn for the three services in a triple-play bundle. As we might have expected, the effect was most pronounced for adoption of these services from the cable company (as compared to adoption overall). We also stressed an important empirical effect in our data that has received little attention in the theoretical literature. The effect was only evident in our data when services experienced "turmoil" in the form of significant diffusion (broadband) or contraction (wired telephone and pay television in 2009, due to recession). The pronounced effects during market contractions highlight bundling's potential role in helping mitigate shrinking markets.

We also found suggestive evidence of broader demand factors shaping bundling's effects, which also lay outside the scope of existing theory. There was a feedback effect through television on broadband in 2009, as many households shifted from having television and broadband to just having broadband. This shift indicated that more households viewed broadband as a substitute for television, and implied a smaller net effect of bundling on broadband churn, because bundlers are less likely to churn television and thus have less need of broadband as a substitute.

Finally, while our econometric techniques were designed to identify the causal (statedependent) effect of bundling on churn, we recognize that they could serve as a screen as well. Consequently, we tested for screening in supplemental analysis, using only suggestive, nondefinitive tests. We found that bundlers tend to have lower income and education levels, as compared to non-bundlers who also purchased all three services. While not conclusive, these differences suggest that bundlers are a selected sample of households, and therefore may differ on other relevant dimensions, including propensity to switch at a later time. However, we also found that controlling for heavy cell-phone use and online-content consumption, which helps predict churn in wired telephone and pay television respectively, had little impact on our measured causal effect of bundling. This suggests that, while these measures may be useful in 
identifying potential service churners, bundlers are not a particularly selected sample along these dimensions. Hence, bundling has an effect on churn that is separate from these household behaviors.

The remainder of this paper is organized as follows. In Section 2, we discuss bundling in the telecommunications industry. In Section 3, we present a simple model of household demand for telecommunications services and service providers. In Section 4, we describe our data, and in Section 5, we detail our econometric models. In Section 6, we present our results, and in Section 7, we provide conclusions.

\section{Bundling in cable services}

As cable firms began offering more services than just cable television, they began experimenting with bundling the triple-play services: wired telephone, pay television, and broadband Internet. While we don't have an official date as to when this practice began, the data we possess only began asking households about bundling behavior in 2006, and at that time well under 15 percent of households in our data were participating. ${ }^{2}$

In general, local cable companies have been able to provide all three services, sometimes at a competitive advantage. This is entirely due to technology differences between these companies and their competitors, e.g., local telephone companies and satellite providers of television services. While cable companies have the infrastructure to provide television, as well as Internet and phone over cable lines, satellite companies are limited in their ability to provide high-speed Internet and telephone services, and local telephone companies have generally been limited in their ability to provide television service (and also provide a slower version of highspeed Internet in the form of DSL). One notable change to this scenario has been Verizon's rollout of fiber optics, allowing it to provide television service, called FiOS, and faster Internet connections. However, this rollout has been slower than predicted, and our data indicate that well under 5 percent of households subscribed to FiOS even by the end of 2009.

\footnotetext{
2 This is consistent with other survey data about bundling. In their study of prices for U.S. broadband services, Greenstein and McDevitt (2011) did not begin their price index for bundled services until 2006, the first year when there was sufficient data from which to construct a price series.
} 
Following the prior literature, we distinguish between pure and mixed bundling. Examples of pure bundling are the bundling of Internet Explorer with Windows, as well as cable channel bundling. Consumers are only given the option of buying the bundles or nothing at all. In contrast, mixed bundling combines wired telephone, pay television, and broadband Internet. In addition to purchasing the bundle, consumers have the option of buying any subset of services instead. Further, the observed pricing of individual services is such that some consumers will make this choice. ${ }^{3}$

Why would cable companies want to offer triple-play bundles? As mentioned in the introduction, there are several standard explanations. Bundling may be an attempt to extend market power; however, the mixed nature of the bundle mitigates this possibility. In addition, bundling could be an attempt at price discrimination; however, it seems intuitive that demand for these technology services would be positively correlated (e.g., because income is a strong determinant of demand for any of them). ${ }^{4}$ The mixed nature also mitigates this possibility. Bundling also may occur because there are economies of scope in production or companies want to simplify the choice set for consumers.

Some key features of triple-play bundling by cable firms make it different from other examples that have been studied, both broadly, as noted, and in communications regulatory settings. ${ }^{5}$ This novelty requires a new explanation for why firms may want to bundle their products. In particular, cable firms offer services, not products. While much, if not all, of the theoretical work on bundled products can include services, or be easily extended to services, the recurring nature of triple-play services allows for bundling to serve a specific purpose. It may lead to bundling playing two distinct roles_either to attract new users or to prevent existing

\footnotetext{
${ }^{3}$ This last feature highlights that the practice truly is mixed bundling, rather than pure bundling disguised as mixed bundling (i.e., if à la carte prices were so high that no one would choose them, then the firms are de facto pure bundling). As noted in Stremersch and Tellis (2002), the fact that firms are engaged in mixed, and not pure, bundling should effectively protect them from any antitrust scrutiny.

${ }^{4}$ In a paper that helped inspire this work, Gandal et al. (2011) empirically shows positively correlated preferences for word processors and spreadsheets.

${ }^{5}$ For example, there has been a long-standing controversy about whether some local telephone firms did or did not offer a full array of mixed bundles in broadband and voice telephone markets, and whether consumers would benefit if they did. This controversy focused on whether consumers could get DSL service without also subscribing to phone service, so-called “naked DSL.” See e.g., http://www.cybertelecom.org/broadband/dslnaked.htm. Our empirical exercise has little to say about the prevalence or relevance of this particular strategy for bundling.
} 
users from leaving. In cable services, users may go for years with the same supplier before reconsidering their arrangement.

We hypothesize that bundling can increase the switching costs of consumers considering an alternative provider or dropping a service, both by forcing a household to restructure its entire telecommunications portfolio when switching and to lose the simplification that comes from having all the services on one bill. For this reason, bundling may have a causal effect on service renewal rates, i.e., households who bundle may be less likely to "churn” their services and/or service providers. In addition, bundling may serve as a screening device designed to get those households least prone to switching products or providers to self-select into a bundle. Specifically, the act of combining services on one bill for a lower price may draw a group of marginal consumers who are relatively less prone to switching.

What are the implications for firm and consumer strategies if bundling creates switching costs? The most obvious concern is that switching costs give sellers market power, allowing them to "raise price above competitors' by an amount almost equal to the switching cost" (Farrell and Shapiro, 1988). That concern generates several related responses. From a policy perspective, switching costs are most worrisome with myopic consumers, who do not forecast the expense. If bundling creates switching costs, policy has less reason to worry about forwardlooking customers, who may ask for price discounts in advance. Empirically, however, these explanations cannot be distinguished in even the most ideal data, because both lead to the same prediction—slower switching at some later time. Interestingly, this last prediction is generally unquestioned in the literature on bundling. Though empirical evidence of switching costs arises in a variety of contexts, there is little empirical evidence of its presence or absence in telecommunications services ${ }^{6}$, or its consequences for bundling.

Beyond this, one may be concerned that switching costs create a barrier to entry (e.g., Porter, 1980). Specifically, incumbents have a cost advantage over potential entrants, and could exploit this to exclude entrants while still making positive profits. Farrell and Shapiro (1988) note that incumbents may not wish to do this if they are unable to distinguish new buyers from existing buyers. However, in this case it is standard practice for cable companies (and other firms) in this industry to price discriminate according to customers' tenure with the company

\footnotetext{
${ }^{6}$ Some recent notable exceptions include Shcherbakov 2007 and Rosston et al. 2010.
} 
(e.g., through introductory, temporary price offers). Consequently, we may not be concerned with bundling as a means to extend market power, because it takes the form of mixed bundling. If it does indeed increase switching costs, however, we may be concerned that it harms competition/consumer welfare via increased long-term market power and stunted take-up of substitute services offered by entrants, such as satellite television or a cable over-builder.

As our results below will suggest, if bundling creates switching costs, it can also help preserve shrinking markets. In our setting, the competing technologies of cell phones and broadband Internet threaten the robustness of wired telephone and even pay-television markets. Cable companies, who provide both services, may use bundling as a means to help keep these markets from shrinking too rapidly.

To conclude this section, we note that a recent study conducted by the United States Federal Communications Commission (FCC) provided some suggestive evidence of a causal link between bundling and churn (FCC, 2010). Specifically, in a survey of over 3,000 adults, 39 percent of broadband users with the choice of more than one provider "said that having to change their current bundle of Internet, TV, and phone service was a major reason for keeping service” (with their current provider). While this is qualitative, inconclusive evidence on just one service, it does provide a "warm lead” for our analysis. It strongly suggests that bundling reduces churn, at least with respect to broadband service providers. Our analysis below will test this hypothesis, as well as several others, using actual household service choices.

\section{A Simple Model}

To anticipate issues we face in the empirical section, we build in this section a simple model of consumer demand for telecommunications services. The triple play covers cable TV, broadband, and telephone services, so we consider these three services in our model.

There exist $N$ households, indexed by $i=\{1, \ldots, N\}$, and three services, indexed by $j=$ $\{1,2,3\}$. For a given household $i$, the utility it derives from purchasing service $j$ at time $t$ is formulated as $U_{j}\left(P_{j t}, X_{i t}\right)$, where $P_{j t}$ is the price of service $j$ at time $t$ and $X_{i t}$ is a vector representing household $i$ 's idiosyncratic characteristics that may affect service utility (e.g., education, income, etc., in our data). We assume that $\partial U_{j} / \partial P_{j t}<0$, so ceteris paribus, utility is 
decreasing in price. In this formulation, we now have the Boolean $D_{i j t}$, which equals one if and only if household $i$ purchases service $j$ at time $t$, represented as:

(1) $D_{i j t}=\left\{\begin{array}{c}1 \text { if } U_{j}\left(P_{j t}, X_{i t}\right)>0 \\ 0 \text { otherwise }\end{array}\right.$

In our case, we observe many $X$ 's (but not price), so we can test the signs of $\partial U_{j} / \partial X_{i k t}$ for each component $k$ of $X$ if we specify an econometric model for $D_{i j t}$.

The primary focus of this paper is to determine whether bundling creates switching costs and consequently reduces churn. Bundling can also affect service adoption patterns. Specifically, bundling enters through a contract price for the three services, which is less than the sum of prices for each service purchased individually. ${ }^{7}$ In a standard model of bundled pricing in a frictionless world, a bundle contract price trades off two revenue streams. Assuming costs of provision are the same (no economies of scope), a bundle sacrifices revenue-i.e., total revenue per customer-from existing customers who would have bought all three services, and gains revenue from additional marginal adopters who purchase an additional service(s) they would otherwise not have purchased. ${ }^{8}$ The implications for a world of switching costs depend on how the friction arises during the dropping of a service. For example, frictions make the adopter more reluctant to drop the service, or switch to another supplier. That might lead to a longer collection of additional revenue or a different price level or both. We will observe proxies for whether there is longer collection, so it is useful to consider this further.

We extend $X_{i t}$ to include bundle status at time $t-1, B_{i t-1}$. Here, $B_{i t-1}$ is a Boolean variable equaling one if household $i$ purchased a bundle at time $t-1$ and zero otherwise. The focus of our empirics will be to identify the sign of $\partial U_{j t} / \partial B_{i t-1}$ because we do not observe price. The impact of switching costs is captured through $\partial U_{j t} / \partial B_{i t-1}$. If bundling raises switching costs, it will appear

\footnotetext{
${ }^{7}$ The presence of switching costs makes it theoretically possible for the bundled price to exceed the sum of each individual service price. However, in practice we are not aware of any cable firm that prices bundles this way. This is almost certainly due to a lack of sufficient market power and the presence of firms offering subsets of services, forcing those that can offer all three to offer mixed bundles, where the bundled price is no higher than the sum of individual prices.

${ }^{8}$ If the bundle saves costs to the supplier, then the model may be extended in a straightforward direction, leading to further discounts.
} 
as if $\partial U_{j t} / \partial B_{i t-1}>0$, that is, as if utility for each service is higher if a bundle was purchased last period. To complete this model, we also include $D_{i j t-1}$ and $A T_{i t-1}$. Here, $A T_{i t-1}$ is a Boolean variable equaling one if household $i$ purchased all three services at time $t$ - 1 , which can overlap with, or differ from, buying a bundle. These additional determinants of utility allow for the possibility of service-level switching costs and spillover effects from prior adoption of other services, respectively. Consequently, the choice model we envision is as follows:

(2) $D_{i j t}=\left\{\begin{array}{c}1 \text { if } U_{j t}\left(P_{j t}, D_{i j t-1}, B_{i t-1}, A T_{i t-1}, X_{i t}\right)>0 \\ 0 \text { otherwise }\end{array}\right.$

We also consider a choice model at the firm level. This is especially appropriate for our study because a single firm - the local cable company-is the predominant provider of tripleplay bundles. If bundling increases switching costs, this could impact households' decisions to switch away from purchasing a service from the local cable company. As with competition, bundling can drive a wedge between the demand for a service and the demand for a particular firm’s service. Further, by analyzing both service-level and service-provider-level demand, we can assess whether bundling's effect is most prominent with regard to dropping a service or dropping a service provider.

Below we show one of the several potential ways to illustrate this. Consider one model of a household $i$ 's decision to purchase service $j$ from the cable company $c$ at time $t$ as:

(3) $D_{i j c t}=\left\{\begin{array}{c}1 \text { if } U_{j c t}\left(P_{j c t}, D_{i j c t-1}, B_{i t-1}, A T_{i t-1}, X_{i t}\right)>U_{j k t}\left(P_{j k t}, D_{i j k t-1}, A T_{i t-1}, X_{i t}\right) \forall k \\ 0 \text { otherwise }\end{array}\right.$

Here, $D_{i j c t}$ is a Boolean representing a given household's decision to buy service $j$ from the cable company at time $t$. We note here that our variable capturing a purchase of all three services at time $t-1\left(A T_{i t-1}\right)$ allows for purchase from any firm, implicitly assuming any spillovers across services will not be specific to whether the other services were purchased from the cable 
company or elsewhere. ${ }^{9}$ The impact of switching costs is captured through $\partial U_{j c t} \partial B_{i t-1}$. If bundling raises switching costs, it will appear as if $\partial U_{j c t} \partial B_{i t-1}>0$, that is, as if utility for each service from the cable company is higher if a bundle was purchased last period.

The choice model has several implications for our econometric exercise. The first two are well known. First, it is obvious that a single cross section of data from households cannot discern whether bundles reduce churn. Bundling's effect can only be seen over time. Second, even with ideal household data an observer will be unable to identify the effect of bundling in the presence of stable demand. If the bundle price does not change over time, and the fundamentals behind demand do not change, the marginal adopter/dropper of service will not change. Pushing this point further, we should only be able to observe an effect from bundling when significant numbers of households drop a service or service provider, because bundling (at time $t-1$ ) is unable to influence the decision of a household that is adding a service or service provider (such households could not have had a triple-play bundle the prior period).

Consider now the details behind the case where demand for a service is falling. This decline may be due to an exogenous increase in the technical capabilities of a service that substitute for one of the three services in the bundle, which induces a decreased demand for it. Abusing notation, that means $U_{j t}(P, X)<U_{j t-1}(P, X)$, namely, utility is lower in time $t$ in comparison to time $t-1$ with the same price and demographics. Bundling will deter dropping of service if it introduces a friction. That is, for the same $\mathrm{X}$, households with bundling will hold on to the service longer. If no such effect is observed, then bundling likely has no effect on churn. As we'll show below, we see this downward shift in demand for both pay television and wired telephone during one of our observed time periods. ${ }^{10}$ This allows us to measure the effect of bundling on households' decisions to purchase these services in general, and to purchase them from the cable company.

Cable firms have clear incentives to deploy bundling if it slows down the dropping of service. One incentive arises from the retention of revenue for a longer period. The second

\footnotetext{
${ }^{9}$ For simplicity, we allow bundling to affect utility only for purchases from the cable company. This allows us to capture any switching costs via an increase in the utility for the cable company rather than a decrease in utility for all other providers, and thus provides a more natural link to our econometric model below.

${ }^{10}$ In this study we do not investigate the causes behind the decline in demand in much detail. The recession of 20082009 was clearly the primary cause. We also follow considerable contemporary commentary and proceed under the assumption that the rise of online entertainment largely helped cause the decline in demand for pay television, while the rise of cell phones and smart phones helped cause the decline in demand for wired telephony.
} 
motive arises from spreading out the time it takes for demand to decline, which slows the rate at which the firm has to adjust the provision of services. The first motive always operates, and by itself, may be sufficient. The second motive could matter in the face of potential non-linear adjustment costs during large changes.

To get a correct measurement of bundling's effect, it is crucial to observe all relevant Xs. If an unobserved $\mathrm{X}$ correlates with the use of bundling, then observing behavior consistent with $\partial U_{j t} / \partial B_{i t-1}>0$ or $\partial U_{j c t} \partial B_{i t-1}>0$ has two interpretations-either bundling or an unobserved $\mathrm{X}$ caused it. One obvious concern is that a given service's price (which is unobserved) may be correlated with prior bundling behavior. If bundling in $t-1$ implies a lower price at time $t$ (as compared to households that didn't bundle in $t-1$ ), then it will appear as though bundling is reducing churn when it is really a price effect. We address this concern in two ways. First, in our empirics we control for location (and other demographics which may be correlated with prices), which can help capture variation in price menus faced by households. Second, we note that individual service prices and the bundle price were generally comprised of a low introductory price, followed by a price increase (usually after one year). To the extent that introductory (but not necessarily post-introductory) bundle prices represented the lowest-cost method of purchasing all three services for consumers, it can be argued that bundlers at time $t-1$ actually faced higher prices than non-bundlers, since the introductory bundle price would no longer be available. Ultimately, our identifying assumption with regard to price is that households that bundled at time $t-1$ did not face substantially different price menus in time $t$ as compared to households that did not bundle at time $t-1$, beyond the controls we include. We discuss this issue further in Section 5.

Another particular concern would be if bundling serves the role of a screen. That is, households with a low propensity to switch services/providers self-select into purchasing a bundle. In this case, an unobserved X (aversion to switching) would be positively correlated with bundling and with the (re-) purchase of a service, causing bundling to appear to reduce switching when it does not. While this is a plausible theory, bundling theory provides an important countervailing force. Households with a bundle entered into a bundled contract because they received a lower price, so the group of bundlers includes some households with lower marginal valuations for services than households who get the same service without bundle. These lower marginal-value households are more likely to drop the service when its demand falls. In this 
case, an unobserved X (low marginal value) is positively correlated with bundling and negatively correlated with (re-) purchase of a service. This would tend to mask a positive causal effect of bundling, if it exists.

In our empirics, we seek some evidence of bundling serving as a screen. The potential presence of such unobserved heterogeneity again highlights the importance of using econometric techniques that isolate it (discussed in Section 5).

For one of our services—-broadband—-demand expanded over the time period we observed, due to an exogenous increase in the capability of the service. ${ }^{11}$ In the context of our model, this means $U_{j t}(P, X)>U_{j t-1}(P, X)$ for any given $\mathrm{P}$ and $\mathrm{X}$. If bundling leads to discounting, does that induce marginal adopters of a new and improving service, such as broadband, to adopt sooner than they would have without bundling? Not necessarily. Fully rational consumers would not change the timing of their behavior if they anticipated all the costs of bundling, including its switching costs. However, myopic or hyperbolic discounting consumers would purchase sooner, as would cash-constrained consumers. For such consumers bundling might generate faster adoption than observed in an otherwise similar population. Whether any of these factors matter is an empirical question.

That said, as mentioned above, bundling's effect is primarily identified through servicedropping, so we do not expect its effect to be large in our data for broadband at the service level. Certainly some households drop broadband even while overall demand expands, but this is likely a very small group. However, when we instead consider broadband from the cable company $\left(D_{i j c t}\right)$, there is likely a significant amount of dropping (churn) occurring. Broadband is still a relatively new service with many providers, meaning many households may still be learning their own preferences across providers. ${ }^{12}$ Consequently, we expect any effect of bundling on broadband to be most evident at the provider, rather than service, level.

\footnotetext{
${ }^{11}$ We feel reasonably safe in assuming the increase is exogenous. The general capabilities of online entertainment were advancing during this time period, raising demand for services across all providers (e.g., Rosston et al., 2010). Some evidence of general increase in the capabilities of broadband providers exists, but the evidence is modest at most. The sparse evidence about quality and price from this period, such as it is, suggests that cable firms were improving their service at a slightly higher rate than phone companies offering DSL, but such improvements were not uniform across all firms or time periods (Greenstein and McDevitt, 2011).

${ }^{12}$ For example, Prince (2011) found some suggestive evidence about households learning their preferred PC brand over time.
} 
In the case of an expanding service such as broadband, we again should be concerned about unobserved heterogeneity driving our results due to bundling serving as a screen. However, because we expect the effect to be identified at the provider level, it is no longer clear that households dropping broadband service from the cable company are marginal adopters (they are merely switching providers, not dropping the service necessarily). Consequently, this is no longer an obvious source of unobserved heterogeneity.

Nevertheless, it is possible the expanding demand for broadband generated an alternative source of unobserved heterogeneity. Specifically, consider the following model. Suppose many households that bundled in period $t-1$ were marginal adopters, and also price sensitive. As demand overall increased, these households were no longer marginal but still price sensitive. This made them especially prone to purchasing the (price-discounted) bundle, and hence retaining broadband service. In this case, an unobserved X (price sensitive and no longer marginal at time $t$ ) is positively correlated with bundling and (re-) purchasing broadband service.

Again, the possible presence of such unobserved heterogeneity requires econometric techniques that isolate it (Section 5).

\section{Data}

\subsection{Description}

The data for this project came from Forrester Research, Inc. Each year since 1997, Forrester has collected thousands of mail surveys of U.S. households on their technology purchases and preferences. The surveys are known as "technographics" and are administered in December of each year. The earliest waves consisted of both independent cross sections and panel data, as a significant number of the same households were purposefully surveyed in consecutive years. Such panel data was used in Prince (2008) and potentially would be ideal for our purposes. Questions regarding triple-play bundling did not appear on the survey until 2006. Unfortunately, by this time repeated sampling of households had ceased. Hence, our usable data consisted of repeated cross sections.

Our analysis focused on the three most recent waves with similar survey structure: 20072009. The data contain a wide range of demographic information. Though Forrester attempts to 
produce a survey that varies the population in different locations and economic circumstances, it also makes no pretense that its sample precisely represents the U.S. population. Hence, this demographic information provides both controls and identification of comparable subgroups across years when constructing a pseudo-panel (as described in Section 5). That is, we used the demographics to make sure our inferences were robust to slight variations in year-to-year composition of the sample of households. The demographic information we utilized includes DMA ${ }^{13}$ education, income, household size, and age.

Beyond demographics, the data contained information on the use and providers of telecom services. Specifically, we could observe, for each year, whether a household subscribed to the following services: wired telephone, pay television (cable or satellite), and broadband Internet (cable, DSL, or satellite). For each of these services, we could observe the provider of a household's subscription (e.g., Comcast, DirecTV, etc.).

However, this information was also limited in some important ways. We did not observe the quality of the service, its price (except in very limited form), ${ }^{14}$ nor the menu of choices put in front of each household. We also did not observe the price of services for the unchosen option(s), such as the prices for the bundle (for those who did not adopt a bundle) or the prices of individual services (for those who did adopt a bundle). Working around these limitations provided one of the principal challenges for our econometric approach.

For reasons discussed in Section 2, we focused our attention on whether or not the provider was the local cable company. This was the firm in the near-unique position to offer a triple-play bundle during the years we observed.

A key variable for our analysis concerned bundling behavior. Each year, Forrester asks the household whether it receives "a bundle of TV, Internet, and phone service from one company on one bill for a package price.” The answer to this question generated our binary "bundle" variable, and we were primarily interested in the effect of bundling behavior in one year on households' service subscription choices the following year.

\footnotetext{
${ }^{13}$ A DMA is a designated market area. DMAs generally coincide with sizeable cities in the United States.

${ }^{14}$ Forrester's surveys generally do not include precise prices or expenditures, but only categories of expenditure, such as $\$ 21-40, \$ 41-60, \$ 61-80$, and so on.
} 
We provide summary statistics for all variables used in years 2007-2009 in Tables 1a-1c below. To be clear, these are the statistics of our sample and do not necessarily represent a representative sample of the U.S. population, so little should be inferred from the sample means.

[Tables 1a 1b and 1c about here]

\section{Empirical Specification and Estimation Strategies}

\subsection{The Empirical Model}

We begin our empirical specification by constructing a model of product and firm choices at the household level. We employ a dynamic linear probability panel data model to explain household choices. We are trying to explain choices among the following services: wired telephone, pay television, broadband Internet, wired telephone with the cable company, pay television with the cable company, and broadband Internet with the cable company. Given a choice variable we want to model, let $Y_{i t}$ be a binary variable that equals one if household $i$ chooses to subscribe to that service/provider in time $t$ and zero otherwise. For example, if we are modeling the wired telephone service decision, $Y_{i t}=1$ if household $i$ subscribes to wired telephone service in time $t$. Our econometric model then looks like this:

(1) $Y_{i t}=\beta_{0}+\beta_{1} X_{i}+\beta_{2} Y_{i t-1}+\beta_{3} B_{i t-1}+\beta_{4} A T_{i t-1}+\varepsilon_{i t}$

Here we assume $X_{i}$ is a vector of household characteristics that are constant over time, ${ }^{15} B_{i t-1}$ is a binary variable indicating whether the household had a bundle at time $t-1, A T_{i t-1}$ is a binary variable indicating whether the household had all three services at time $t$ - 1 (bundled or not), and $\varepsilon_{\mathrm{it}}$ constitutes unobservables (e.g., a child who strongly wants an active telephone in her room) for household $i$ at time $t$ that affects its choice on $Y$. The inclusion of $Y_{i t-1}$ and $A T_{i t-1}$ is important, as they respectively control for switching costs at the individual service level and spillover effects from purchasing either of the other two services.

The primary goal of our empirical analysis is to assess whether $\beta_{3}>0$. This parameter literally measures the difference in churn rates at time $t$, between bundlers and non-bundlers (at

\footnotetext{
${ }^{15}$ The importance of $\mathrm{X}$ being fixed over time will be made explicit below.
} 
time $t-1$ ). This is because $\beta_{3}$ measures change in the rate of service adoption caused by a change in prior bundling status, holding the other variables fixed. Such a measure is only possible if prior service adoption occurred (i.e., $\mathrm{Y}_{\mathrm{it}-1}=1$ ), because prior adoption not occurring implies prior bundling not occurring. Thus, $\beta_{3}$ measures the difference in service adoption rates between prior adopters with a bundle and prior adopters without a bundle; such a difference can be due only to differences in churn rates.

Of course, there is reason to believe $Y_{i t-1}, A T_{i t-1}$, and $B_{i t-1}$ are endogenous. Put another way, we have reason to be concerned that these variables are correlated with unobservables that influence the service choice of household $i$ at time $t\left(Y_{i t}\right)$. For example, if a household has an inherent, persistent preference for wired-telephone connection (captured in both $\varepsilon_{i t-1}$ and $\varepsilon_{i t}$ ), it likely chose to purchase this service at time $t-1$ (i.e., $Y_{i t-1}=1$ ), and will likely choose to purchase this service at time $t$ as well (i.e., $Y_{i t}=1$ ). This will make it appear as though the purchase decision at $t-1$ influenced the purchase decision at time $t$, when in fact the household's persistent preference for wired telephone drove both decisions. Beyond this, because we only have repeated cross-sectional data, we cannot actually observe $Y_{i t-1}, A T_{i t-1 \text {, }}$ and $B_{i t-1}$ for a given household $i$. We address both of these concerns below.

\subsection{Estimation Using a Pseudo Panel}

If our data from Forrester were a panel, we would execute standard-panel data methods to estimate equation (1). However, because we have only repeated cross-sectional data, we must construct and utilize a pseudo (or synthetic) panel using these cross-sectional data. Such an approach began with Deaton (1985), and has been developed further by several subsequent papers in the econometrics literature (e.g., Moffitt, 1993; Collado, 1997; McKenzie, 2004; Verbeek and Vella, 2005). These techniques have most often been applied in macroeconomics, labor economics, and development economics, where available data are often in the form of repeated cross sections (e.g., Cuesta et al., 2011).

In general, constructing a pseudo panel involves identifying a set of time-invariant criteria with which to construct data groupings. In our case, these criteria will consist of observable demographic characteristics that we believe are stable over a short period of time 
(one year). ${ }^{16}$ We reason that information about lagged variables $\left(Y_{i t-1}, A T_{i t-1}\right.$, and $\left.B_{i t-1}\right)$ for household $i$ can be gathered by observing $Y_{h t-1}, A T_{h t-1}$, and $B_{h t-1}$ for households $h$ in the same group as household $i$. To this end, we follow the approach described in Moffitt (1993) and further discussed in Verbeek and Vella (2005). Specifically, for each household $i$ in a given group $g$, we replace $Y_{i t-1}, A T_{i t-1}$, and $B_{i t-1}$ with $\bar{Y}_{g t-1}, \overline{A T}_{g t-1}$, and $\bar{B}_{g t-1}$, respectively. The latter three variables are the averages for $Y, A T$, and $B$ in group $g$ at time $t-1$.

The above methodology has two key merits. First, it fills in the missing pieces in equation (1). For a given household $i$ that we observe at time $t$, the averages for $Y, A T$, and $B$ in the same group as household $i$ at time $t-1$ intuitively provide information about $Y_{i t-1}, A T_{i t-1}$, and $B_{i t-1}$. Second, it actually mitigates endogeneity concerns for our lagged variables. Whereas with panel data, we would have a clear concern that $\operatorname{Cov}\left(Y_{i t-1}, \varepsilon_{i t}\right) \neq 0, \operatorname{Cov}\left(A T_{i t-1}, \varepsilon_{i t}\right) \neq 0$, and/or $\operatorname{Cov}\left(B_{i t-1}, \varepsilon_{i t}\right) \neq 0$ due to re-observation of household $i$, this is not the problem we face when replacing lagged variables with group averages at $t-1$. Moffitt (1993) describes the above approach as an application of simple 2SLS, where in the first stage, we regress $Y_{h t-1}, A T_{h t-1}$, and $B_{h t-1}$ on group dummies. Then, in the second stage, we use the predicted values from the first stage (which will simply be group averages) when estimating equation (1).

While the justification of Moffitt (1993) for using group means as instruments is intuitive, we follow the discussion in Verbeek and Vella (2005) to pin down the assumptions we employ for identification. We begin by reformulating equation (1):

$$
\begin{aligned}
& \text { (2) } Y_{i t}=\beta_{0}+\beta_{1} X_{i}+\beta_{2} \bar{Y}_{g t-1}+\beta_{3} \bar{B}_{g t-1}+\beta_{4} \overline{A T}_{g t-1}+\left(\varepsilon_{i t}+\beta_{2}\left(Y_{i t-1}-\bar{Y}_{g t-1}\right)+\right. \\
& \left.\beta_{3}\left(B_{i t-1}-\bar{B}_{g t-1}\right)+\beta_{4}\left(A T_{i t-1}-\overline{A T}_{g t-1}\right)\right)
\end{aligned}
$$

Given a choice of groupings, it is this equation we will estimate with our data, where the terms in parentheses constitute our "error term.” Written this way, the use of group averages essentially introduces measurement error, in the form of $Y_{i t-1}-\bar{Y}_{g t-1}, B_{i t-1}-\bar{B}_{g t-1}$, and $A T_{i t-1}-$ $\bar{A} T_{g t-1}$. As Verbeek and Vella (2005) note, this measurement error is uncorrelated with our

\footnotetext{
${ }^{16}$ The stable demographics are partially a consequence of the research design employed by Forrester. In the presence of large changes in the demographic makeup of the sample before and after an econometric "treatment," a different approach is potentially more appropriate. See, for example, Hong (2011).
} 
explanatory variables, in particular $\bar{Y}_{g t-1}, \bar{B}_{g t-1}$, and $\overline{A T}_{g t-1}$. Hence, this eliminates concerns about a classical errors-in-variables (CEV) problem that could induce bias ${ }^{17}$.

Formulating the econometric model as we do in equation (2) allows us to determine the necessary assumptions for our parameters to be identified. On a broad level, we simply need our composite error term to be uncorrelated with our explanatory variables. However, by considering each part of the composite error term, we can determine the believability of this assumption. To begin, as noted above, the measurement error is not correlated with the group averages by construction. In addition, the measurement error is not correlated with $\mathrm{X}_{\mathrm{i}}$ because $\mathrm{X}_{\mathrm{i}}$ does not vary over time (Verbeek and Vella, 2005).

This means identification depends on a key assumption, that the idiosyncratic term $\left(\varepsilon_{i t}\right)$ is uncorrelated with the explanatory variables. Maintaining that $\varepsilon_{\mathrm{it}}$ and $\mathrm{X}_{\mathrm{i}}$ are uncorrelated is standard, as the components of $\mathrm{X}_{\mathrm{i}}$ play the role of “exogenous” demographic controls. Further, we note here that our controls help account for price variations (which we cannot observe). Specifically, telecom service prices generally vary regionally. Hence, our regional DMA controls account for a great deal of unobserved price variation.

Assuming $\varepsilon_{\text {it }}$ is uncorrelated with $\bar{Y}_{g t-1}, \bar{B}_{g t-1}$, and $\overline{A T}_{g t-1}$ could be more problematic. As noted in Verbeek and Vella (2005), this requires us to believe the unobservables harbor no "group effects.” The existence of such group effects creates obvious concern for bias in $\beta_{2}$ because they directly imply correlation between $\bar{Y}_{g t-1}$ and $\varepsilon_{\mathrm{it}}$; however, their potential for bias in $\beta_{3}$ and $\beta_{4}$ depends on whether we believe these group effects that impact $Y$ are also correlated with $B$ and/or $A T$. Regardless, even if we believe any group effects would be uncorrelated with $B$ and $A T$, a bias in $\beta_{2}$ can generate a bias in $\beta_{3}$ and/or $\beta_{4}$. Hence, to have the greatest faith in our estimates, we want to maintain the assumption of no group effects.

In principle, we can completely eliminate the presence of group effects in our unobservables by including group fixed effects in X. However, having only two waves of usable

\footnotetext{
${ }^{17}$ To further illustrate this point, we demonstrate this claim with regard to our bundle variable. Specifically, we note that $\operatorname{Cov}\left(B_{i t-1}-\bar{B}_{g t-1}, \bar{B}_{g t-1}\right)=E\left(\left(B_{i t-1}-\bar{B}_{g t-1}\right) * \bar{B}_{g t-1}\right)-E\left(B_{i t-1}-\bar{B}_{g t-1}\right) * E\left(\bar{B}_{g t-1}\right)=E\left(B_{i t-1} *\right.$ Bgt $-1-E B g t-1 * B g t-1-0=1 \mathrm{Ng} * N g * E$ Bit $-12-1 \mathrm{Ng} 2 * N g 2 *$ EBit $-12=0$. Here, $\mathrm{N}_{\mathrm{g}}$ is the number of observed households in group $\mathrm{g}$.
} 
data severely limits remaining variation in our variables. Further, we believe most of our identification power resides in our second wave of data, which exhibits market contraction. Therefore, we proceed without group fixed effects, and maintain the assumption that no group effects beyond those captured in $\mathrm{X}$ exist. This implies that cross-sectional variation in unobservables (having controlled for $\mathrm{X}$ ) are transient. The believability of this assumption depends on our method for constructing groups (and the persistence of our results across specifications), which we now describe.

We construct our groups using classic demographic measures in our data. These include DMA, income level, education level, household size, and age. ${ }^{18}$ The question then is where to draw the boundaries for the groups, and it is here that we face a tradeoff, part of which is summarized in Cuesta et al. (2011). The tradeoff for our analysis is summarized as follows. As we draw tighter boundaries, we have more groups but a smaller number of observations per group. With more groups, we generate more variation in our variables (in particular with regard to our variables measured at the group level), creating more "observations" and hence greater identification power. More groups also allow us to include more "X" controls. With more controls, the existence of "group effects" in the unobservables becomes less likely, thus making our assumption that $\varepsilon_{\mathrm{it}}$ is uncorrelated with $\bar{Y}_{g t-1}, \overline{A T}_{g t-1}$, and $\bar{B}_{g t-1}$ more credible. However, with fewer observations per group, the group means used in the regression will be poor estimates of the true population mean for that group. This essentially will inflate the variance in our composite error term, and hence tend to inflate standard errors.

Recognizing this tradeoff when constructing our groupings, we opt for a larger number of groups because it allows us to include important controls without completely eliminating variation in our averaged variables (bundle, adoption of all three services, and prior adoption). Perhaps the most important controls in our analyses are DMA-level dummy variables. These controls net out persistent price and service quality differences across locations, which certainly exist and we do not directly observe. Consequently, our benchmark results group our observations according to DMA, income, education, household size, and age. Here, the

\footnotetext{
${ }^{18}$ Note that the control for DMA precludes identifying any characterization of the competitive supply if it is shared by all users within a DMA. So, for example, if FiOS or RCN is in some DMAs and not others, the dummies will capture this facet of the situation, and that does not shape the estimates of bundling. If there is a change in FiOS or RCN over time, the dummy coefficient estimates will be different across the years, which prevents such changes from biasing our measurements of interest.
} 
categories for the last four measures are as defined in Tables 1a-1c. We consider some coarser groupings; however, the importance of including DMA-level dummies precludes us from coarsening our groupings too much. For example, we do not conduct analysis for observations grouped only at the DMA level. In this case, DMA-level dummies are impossible to include; without them, our results would be highly suspect because we'd have inadequate controls for unobservable price variation and service quality variation.

Our primary use of tight group boundaries can result in very few observations in a group. In fact, in some cases, a non-empty group in one year, say 2008, may be empty in the prior year (i.e., 2007) in our data. Left as is, these observations would be dropped in our analysis. However, to fully explore our results when imposing tight boundaries, instead of dropping observations that belong to groups that were empty the prior year, we identify their nearest neighbors and use their average measures for $\bar{Y}_{g t-1}, \overline{A T}_{g t-1}$, and $\bar{B}_{g t-1}$. Specifically, for a given household $i$ in year $t$ that belongs to a group $g$ that was empty in $t-1$, we identify the households in $t-1$ "nearest" to that group, and use them to construct $\bar{Y}_{g t-1}, \overline{A T}_{g t-1}$, and $\bar{B}_{g t-1}$.

We identify the nearest household(s) following Abadie et al. (2004), employing a vector norm metric along the dimensions used to determine the groups. For example, if a group $g$ is defined as households in St. Louis with income of $\$ 50-\$ 70 \mathrm{~K}$, a college education, four members, and head of household ages 45-54, the closest group may be households in St. Louis with income $\$ 50-\$ 70 \mathrm{~K}$, some college, four members, and head of household ages $45-54$. We would then use the sample averages for this neighboring group for $\bar{Y}_{g t-1}, \overline{A T}_{g t-1}$, and $\bar{B}_{g t-1}$.

Implementing this approach for narrowly defined groups will increase measurement error but allow us to use all observations in our year pairings (2007 and 2008, and 2008 and 2009). It also opens the possibility for a CEV problem, because we can no longer assume the measurement error is uncorrelated with the group mean used for each observation. Hence, the tradeoff of using this approach is quite clear. On the one hand, it increases the number of observations used; this merit is especially important if one has a dataset with many cells that are non-empty in one year and empty in another. On the other hand, this approach introduces the possibility of attenuation bias due to a CEV problem. 


\subsection{Testing for Screening and Selection}

As noted above, price savings offered by bundling may entice households with lower marginal valuation. A household's inherent preference for inertia also may induce selection into a bundle, though it is something unobservable to both service providers and the econometrician.

We address screening issues in two ways. First, we attempt to further establish that our estimates from equation (2) are causal (and not due to screening) by including further controls. In particular, we estimate this model controlling for heavy cell-phone use at time t-1 (for wired telephone regressions) and heavy online content consumption at time t-1 (for pay television regressions). These added controls clearly predict churn rates for some of our services, and if bundling selects households along these dimensions, our causal inference may be biased.

Second, we recognize that bundling may have a causal effect on service purchases while also playing the role of a screen. Assuming our causal estimates withstand our added controls, we can at least attempt to assess whether bundling households have different characteristics than non-bundling households. Because we do not observe individual households’ bundle statuses from previous years, we cannot test for a correlation with the unobservables in the error term $\left(\varepsilon_{\mathrm{it}}\right)$ via, e.g., a Hausman test. Despite such limitations, we still have several options. We can at least test whether, along the demographic measures we observe, bundlers significantly differ from non-bundlers who also purchased all three services. Any differences we find would suggest that bundling plays a screening role-picking off households that are less inclined to churn services and/or service providers. Any implied screening effect that we find would supplement causal effects we identify, because, by design, our econometric model above abstracts away from any correlation between unobserved household characteristics and bundling status.

\section{Results}

\subsection{Does Bundling Reduce Churn?}

In Tables $2 \mathrm{a}-2 \mathrm{~d}$, we present our results ${ }^{19}$ for our six choice variables (wired telephone, pay television, broadband Internet, wired telephone with the cable company, pay television with

\footnotetext{
${ }^{19}$ Because we are using a linear probability model, there is heteroskedasticity by construction. All of our results contain robust standard errors.
} 
the cable company, and broadband with the cable company) for 2008 and 2009. The key estimates are in the main tables and the full results are in the appendix.

Before looking at the results for bundling we examined all the estimates for symptoms that the model performs reasonably well. For example, as expected, broadband demand was monotonic in income (increasing), education (increasing), size of household (increasing except at the highest level), and age of head of household (decreasing, especially after 65). Further, as we might expect, we found evidence of switching costs for each service individually (captured by positive coefficients for $\left.Y_{i t-1}\right)$. For example, subscription to pay television at time $t-1$ increased the likelihood of subscribing to pay television at time $t$. Given our control for this effect, any effect we found for bundling was above and beyond any switching costs at the individual service level. Lastly, it is interesting to note that a purchase of the other two services at time $t-1$ appeared to generate very little, if any, spillover effects for any of the services. We will translate these estimates into their quantitative and economic importance below.

The results indicated an effect of households' bundle status, but it appeared to differ across services/providers and years. In particular, in 2008 bundling appeared to reduce churn with respect to broadband, broadband with the cable company, and wired telephone with the cable company. In 2009 bundling appeared to reduce churn with respect to pay television, wired telephone with the cable company, and pay television with the cable company ${ }^{20}$. This pattern of results held up well to different groupings we tried where the number of groups remained large.

The only instances where we observed some differences involved broadband. Specifically, we found a significant effect of bundling for broadband and broadband with cable company for some of our alternative groupings (e.g., grouping along DMA, income, education, and household size-no longer grouping on age). ${ }^{21}$ We discuss this peculiarity further below.

\footnotetext{
${ }^{20}$ Note that our results for the cable company still use the same bundle dummy variable, which may include noncable bundles (although a relatively small proportion); hence, these are likely lower bounds on bundling's effect on service purchases at the cable company. Our results generally hold if we use information on service purchases to deduce whether the bundle was with the cable company; however, constructing such a variable introduces extra measurement error (coming from both the bundle response and the service purchase response), resulting in some apparent, minor attenuation bias in our 2007-2008 results.

${ }^{21}$ These results are available from the authors upon request. We did not include them because generating one small observation involves a lot of output.
} 
Finally, we estimated our econometric model using the datasets we constructed using a nearest-neighbor algorithm (described in Section 5). The results are in Tables 3a-3d. They mimic those in Tables 2a-2d very strongly in the demographics, and are similar in our core estimates, bundling. The smaller coefficient estimates suggest a CEV problem, which generates attenuation bias (as discussed in Section 5). However, the relative sizes of the bundle coefficients across services and years are notably similar to those in Tables 2a-2d. Hence, it appears that this method of extending our pseudo panel can be effective, although it can come at the expense of some attenuation bias, at least in our circumstance.

Overall, these results suggest that bundling reduces churn in many instances, but the variance in its effect is curious. We believe two fundamental drivers produce this pattern. The first is very straightforward—effects from bundling are more visible in "turbulent” markets. Put another way, we only expect an effect from bundling in markets where a significant amount of turnover in services and/or service providers exists. At the time of our data, wired telephone and pay television were widely diffused, while broadband was still in the midst of diffusing. Hence, we may only expect to see an effect on telephone and pay television if the demand for them declines, and broadband (particularly broadband with the cable company) if demand grows (as discussed in Section 3).

As it turned out, economic forces strongly trended toward demand declines in the two services vulnerable to it. The United States suffered a deep recession during the time period of our data, whose nadir was sometime in 2009. Consequently, wired-telephone and pay-television markets experienced a great deal of turmoil in the form of service-dropping between 2008 and 2009. In Table 4, we present simple summary statistics for overall adoption rates for our six choice variables. In it we see the wired-telephone and pay-television markets were very stable between 2007 and 2008, but both took major downturns between 2008 and 2009. Concurrently, we see broadband continue a steady diffusion, moving from 59 percent to 62 percent to 68 percent of our sample between 2007 and 2009.

If the effects of bundling are generally only visible in turbulent markets, our results suggest that bundling reduces churn for all services and service providers, and we simply observed it during a time of market turbulence. While this is our general conclusion based on our findings, the aforementioned variance in the measured effect of bundling on broadband and 
broadband from the cable company remains. Specifically, we measured an effect in 2008, and in 2009 we didn't see an effect using our primary groupings, but do in some alternative groupings (e.g., grouping by DMA, income, education, and household size only).

We contend that this is likely due to a feedback effect from bundling's effect on pay television, which sometimes masks its effect on broadband. Specifically, as subscription to pay television dramatically declined in 2009, we saw the emergence of a new phenomenon. During this time, there was a significant shift by households toward subscribing to broadband Internet and not subscribing to pay television.

In Table 5, we illustrate this shift. Table 5 shows the proportions of households for all four combinations of television and broadband subscription statuses across our three years of data. In 2009 the proportion of households with broadband and no television dramatically increased compared to 2008, while all other proportions remained relatively stable or declined.

The shift is of comparable magnitude to the shift in television subscription over the same period, suggesting it represents a significant number of households moving from subscribing to television and broadband (or possibly television and no broadband) to subscribing only to broadband. ${ }^{22}$

Table 5 indicates that, for a subset of the population, broadband became a substitute for pay television. To corroborate this claim, we note that the most likely group to choose to substitute broadband for television in the face of a recession would be those most capable of using broadband to view programming content and have the greatest need to save money. In the context of our demographic measures, this group likely consists of younger, educated households with less income. Table 6 presents and compares across 2008 and 2009 the averages of our demographic measures for the group of households with broadband service but no television service. Here, we see that this group became younger and more educated, and had lower income in 2009, as expected.

\footnotetext{
${ }^{22}$ It may appear from Table 5 that the rise in the proportion of households with broadband and no TV mirrors the drop in households with TV and no broadband. However, as broadband continued to diffuse during this time, the households newly adopting broadband were likely from the group with TV and no broadband, thus moving them into the group with TV and broadband. The size of the latter group remained constant because pre-existing members concurrently moved to the group with broadband and no TV.
} 
As further corroboration of this idea, we note that the availability of streaming online content was increasing at a rapid pace by 2009. Major providers such as Hulu and Netflix began establishing a significant presence in this market around this time. Specifically, Hulu launched in March 2008, and Netflix began offering unlimited Internet streaming in January 2008.

If a significant number of households in 2009 substituted broadband for pay television, our measured effect of bundling on broadband and broadband from the cable company in 2009 could be reduced via a feedback effect. This is because, for households dropping television service, broadband service is more likely. However, this group is also less likely to have bundled, because bundling reduces churn. Hence, the measured effect of bundling on broadband will be less than its "true" effect, because the measured effect captures both the effect of switching costs for broadband and the effect of less churn in television.

Taken as a whole, our results indicate the following. Bundling reduces churn, and its effect is most visible when markets are turbulent. In addition, broadband appears to have emerged as a substitute for television for a significant number of households in 2009. Bundling's churn-reducing effect on television likely prevented some households from dropping television to go “broadband-only,” thus creating a smaller net effect of bundling on broadband.

The effect also appears to be economically significant. For example, in 2009, bundling the prior year increased the likelihood of subscribing to pay television and wired telephone from the cable company by 2.2 and 3.5 percentage points, respectively. This not only represents a substantial revenue boost for 2009, but to the extent that bundling persists (and household bundling increased over the time period we observe), it could mean increased revenues for multiple years.

As an attempt to quantify bundling's effect, we conduct a simple back-of-the-envelope calculation of preserved revenue (in the face of declining demand) that could be attributed to bundling. We focus our measurement on pay television, as this is one of our declining markets in 2009 both at the product level and for cable companies in particular. ${ }^{23}$ The estimates in Table $2 \mathrm{~d}$

\footnotetext{
${ }^{23}$ Wired telephone also declined in 2009, however not at the cable company level, as shown in Table 4 . The increase in wired telephone at the cable company in spite of an overall decline is almost certainly due to concurrent switching from traditional wired telephone to VOIP. The effect of bundling for wired telephone for the cable company would
} 
indicate that the purchase rate of pay television from cable companies in 2009 was 2.2 percentage points higher when a household had a bundle in 2008, compared to when it did not. From Table 1b, we see that 27.9 percent of households in our study had a triple-play bundle in 2008. Further, even if we weight our observations to match the U.S. population demographically, this percentage reaches a similar number. Therefore, a simple calculation of revenue preservation for 2009 would be:

Annual Revenue Preservation $=12 *($ Bundle Revenue $-($ Phone + Broadband Revenue $) *(\#$ of U.S. Households $) *(0.279) *(0.022)$

Using a conservative estimate of \$30 per month for the difference in bundle revenue and (phone+broadband) revenue, ${ }^{24}$ and 117 million as the number of U.S. households, the preserved revenue then is $\$ 259$ million, which is a substantial number for the entire market. Further, this is revenue for just one year-bundling effects could certainly persist for a longer period of time.

As the above calculation highlights, the long-term impact of bundling on revenue should factor into a firm's consideration of tradeoffs when deciding if and how to bundle (as discussed in Section3). Further, as illustrated, it may play a substantial role in helping stave off contraction in the wired-telephone and pay-television markets.

\subsection{Bundling as a Screen and Selection}

As discussed in Section 5.3, bundling could serve the role of a screen by identifying a set of households least inclined to drop services or service providers. If this is the case, there are two possibilities: 1) only screening is occurring, and our measures of bundling's causal effect are biased due to this practice; or 2) screening is occurring in addition to bundling's causal effect on churn. Possibility \#1 can occur only if unobservable household characteristics are correlated with average bundling behavior of similar households (in the same group) the prior period. The recession of 2009 helped generate variation in our groups over time. However, there still may be persistent, unobserved "group effects" correlated with bundling and lower churn rates. We further investigate this possibility by including some additional controls. Specifically, we

then more properly be characterized as revenue enhancing rather than preserving, although both circumstances result in higher revenues than would have occurred otherwise.

${ }^{24}$ In our dataset, the average difference is approximately \$37 per month (using very coarse price measurements). 
measure whether households at time $t-1$ are heavy cell-phone users (measured as daily sending and/or receiving of text messages) or heavy online-content consumers (measured as weekly watching of online television shows). We then control for these in our estimates of equation (2) for wired telephone and pay television, respectively. In both cases, while these variables do have some explanatory power for churn (particularly in 2009), their inclusion has virtually no impact on our bundling estimates. This provides further evidence that bundling does in fact have a causal effect (not confounded by screening).

The totality of our empirical analysis leads us to believe that, if screening is occurring, it supplements a causal bundling effect on churn. We can only provide suggestive evidence of bundling playing the role of a screen. We do this by conducting simple comparisons along our demographic measures between households who bundled and households who purchased all three services but did not bundle. We present these results in Table 7.

Here, we see that bundlers generally have lower income and lower education levels. Further, there is some mild evidence that they live in larger households and are younger. These findings illustrate non-trivial differences between bundlers and non-bundlers of all three services

along basic demographics, suggesting bundlers are a somewhat selected group. To the extent that selection along these dimensions is related to selection according to propensity to switch, bundling may play the role of a screen, in addition to its direct impact on switching costs. However, the importance of income suggests that bundling probably also picks up users who are sensitive to price, namely, marginal demanders. Overall, bundling probably combines both.

\section{Discussion and Conclusions}

In this paper, we presented a novel explanation for firms to bundle that is particularly pertinent in recurrent service industries — reduction of churn. We tested whether bundling appears to increase switching costs by analyzing household-level choices for telecommunications services that are often packaged in a triple play: wired telephone, pay television (satellite or cable), and broadband Internet.

We found that bundling does reduce churn for the three services in a triple-play bundle. The effect is most pronounced for adoption of these services from the cable company, and the 
effect is only evident in our data when services experienced "turmoil." We also found suggestive evidence of broader demand factors shaping the effect of bundling, but these effects lie outside the scope of existing theory. More households appear to view broadband as a substitute for television, which implies a smaller net effect of bundling on broadband churn. Finally, we tested for screening in supplemental analysis. While not conclusive, these differences suggest that bundlers are a selected sample of households, and therefore may differ on other relevant dimensions, including propensity to switch.

Our findings have several implications. First, they imply that bundling firms can earn higher margins on bundling customers than they otherwise would if bundling did not create switching costs. However, to the extent that households recognize the increased switching costs they impose, bundling firms may need to offer their bundles at especially low introductory prices (Farrell and Shapiro, 1988). In addition, bundling may dissuade entry, as a significant proportion of customers are "locked in" to their service/provider choices through a bundle. Potential entrants such as Verizon's FiOS or AT\&T's U-Verse may have reduced incentives to enter markets where a significant number of potential customers already have a bundle with an incumbent. Third, bundling may help firms slow down contracting markets. In our setting, tripleplay bundling appears to help mitigate demand contractions in both wired telephone and cable television. Next, to the extent that bundling serves as a screen, it can be useful for bundling firms in optimizing efforts to retain customers, recognizing that such efforts are best used on nonbundlers.

We note that the welfare effects of bundling in our case were ambiguous, as they depended on the nature of switching costs that are created. If bundles only increase the hassle of switching, the welfare effects are likely negative; however, if they increase realized value that customers are reluctant to relinquish via switching, welfare gains could result.

Our findings also motivate further work on the role of bundling in other contexts. We saw a variety of areas where users chose a supplier for services and then periodically considered switching between vendors. Our work motivates further investigation of markets where such user behavior dominates economic conduct. For example, many software markets have increasingly moved away from packaged formats and toward service models, and bundling practices are quite 
common in that market. We look forward to further empirical evidence on the relevance of such practices to competitive outcomes. 


\section{References}

Abadie, A., D. Drukker, J. Herr, and G. Imbens. 2004. Implementing matching estimators for average treatment effects in stata. The Stata Journal 1:1-18.

Adams, W., and J. Yellen. 1976. Commodity bundling and the burden of monopoly. Quarterly Journal of Economics 90:475-498.

Armstrong, M. 1996. Multiproduct nonlinear pricing. Econometrica 64 (1): 51-75.

Bakos, Y., and E. Brynjolfsson. 1999. Bundling information goods: Pricing, profits, and efficiency. Management Science 45 (2): 1613-1630.

Carbajo, J., D. De Meza, and D. Seidman. 1990. A strategic motivation for commodity bundling. The Journal of Industrial Economics 38:283-298.

Chen, Y. 1997. Equilibrium product bundling. Journal of Business 70 (1): 85-103.

Choi, J. P. 1998. Tying and innovation: A dynamic analysis of tying arrangements. Economic Journal.114:83-101.

Collado, M. 1997. Estimating dynamic models from time series of independent cross-sections. Journal of Econometrics 82:37-62.

Crawford, G. 2008. The discriminatory incentives to bundle in the cable television industry. Quantitative Marketing and Economics 6:41-78.

Cuesta, J., H. Nopo, and G. Pizzolitto. 2011. Using pseudo-panels to measure income mobility in Latin America. Review of Income and Wealth 57:224-246.

Deaton, A. 1985. Panel data from time series of cross-sections. Journal of Econometrics 30:109126.

Farrell, J., and P. Klemperer. 2007. Coordination and lock-in: Competition with network effects and switching costs. In Handbook of industrial organization, vol. 3, ed. M. Armstrong and R. Porter, 1970-2056. Amsterdam: Elsevier.

Farrell, J., and C. Shapiro. 1988. Dynamic competition with switching costs. RAND Journal of Economics 19 (1): 123-137.

Federal Communications Commission. 2010. Broadband decisions: What drives consumers to switch—or stick with—-their broadband Internet provider. FCC working paper.

Gandal, N., S. Markovich, and M. Riordan. 2011. Ain’t it 'suite’? Bundling in the PC office software market. Working paper. 
Greenstein, Shane, and Ryan McDevitt. 2011. Evidence of a modest price decline in U.S. broadband services. Information and Economic Policy 23 (2): 200-211.

Hong, Seung-Hyun. Forthcoming. Measuring the effect of Napster on recorded music sales: Difference-in-differences estimates under compositional changes. Journal of Applied Econometrics, https://netfiles.uiuc.edu/hyunhong/www/napster.pdf (accessed October 2011). Israel, M. 2005. Tenure dependence in consumer-firm relationships: An empirical analysis of consumer departures from automobile insurance firms. RAND Journal of Economics 36 (1): 165-192.

Lancaster, K. 1971. Consumer demand: A new approach. New York: Columbia University Press. McAfee, R., J. McMillan, and M. Whinston. 1989. Multiproduct monopoly, commodity bundling, and correlation of values. Quarterly Journal of Economics 103:371-383.

McKenzie, D. 2004. Asymptotic theory for heterogeneous dynamic pseudo-panels. Journal of Econometrics 120:235-262.

Moffitt, R. 1993. Identification and estimation of dynamic models with a time series of repeated cross-sections. Journal of Econometrics 59:99-123.

Nalebuff, B. 2004. Bundling as an entry barrier. Quarterly Journal of Economics 119 (1): 159187.

Porter, M. 1980. Competitive strategy. New York: Free Press.

Prince, J. 2008. Repeat purchase amid rapid quality improvement: Structural estimation of demand for personal computers. Journal of Economics and Management Strategy 17 (1): 1-33.

Prince, J. Forthcoming. Relating inertia and experience in technology markets: An analysis of households' personal computer choices. Applied Economics.

Rosston, Greg, Scott Savage, and Donald Waldman. 2010. Household demand for broadband Internet in 2010. The B.E. Journal of Economic Analysis \& Policy 10 (1): article 79. DOI: 10.2202/1935-1682.2541.

Salinger, M. 1995. A graphical analysis of bundling. Journal of Business 68 (1): 85-98.

Schmalensee, R. 1982. Commodity bundling by single-product monopolies. Journal of Law and Economics 25:67-71.

Shapiro, C., and H. Varian. 1999. Information rules. Cambridge, MA: Harvard Business School Press. 
Shcherbakov, O. 2007. Measuring consumer switching costs in the television industry. Working paper.

Stigler, G. 1968. A note on block booking. In The organization of industry, ed. G. Stigler and R. D. Irwin. Chicago: University of Chicago Press.

Stole, L. 2007. Price discrimination and competition. In Handbook of industrial organization, vol. 3, ed. M. Armstrong and R. Porter. Amsterdam: Elsevier.

Stremersch, S., and G. Tellis. 2002. Strategic bundling of products and prices: A new synthesis for marketing. Journal of Marketing 66:55-72.

Verbeek, M., and F. Vella. 2005. Estimating dynamic models from repeated cross-sections. Journal of Econometrics 127:83-102.

Whinston, M. 1990. Tying, foreclosure, and exclusion. American Economic Review 80 (4): $837-$ 859. 
Table 1a

Summary Statistics 2007

\begin{tabular}{|c|c|c|c|}
\hline Variable & $\underline{\text { Mean }}$ & Std. Dev. & \# of Obs. \\
\hline Telephone & 0.907999 & 0.289031 & 49847 \\
\hline Television & 0.828355 & 0.377076 & 49847 \\
\hline Broadband & 0.593857 & 0.491117 & 49847 \\
\hline TelephoneCableCo & 0.105242 & 0.306868 & 49847 \\
\hline TelevisionCableCo & 0.538046 & 0.498555 & 49847 \\
\hline BroadbandCableCo & 0.253837 & 0.43521 & 49847 \\
\hline Bundle & 0.225089 & 0.417645 & 49847 \\
\hline All Three Services & 0.485967 & 0.499808 & 49847 \\
\hline Less Than H.S. & 0.05563 & 0.229209 & 49847 \\
\hline H.S. Degree & 0.24846 & 0.432124 & 49847 \\
\hline Some College & 0.343792 & 0.474978 & 49847 \\
\hline College Degree & 0.215861 & 0.411422 & 49847 \\
\hline Graduate Degree & 0.136257 & 0.343065 & 49847 \\
\hline$<25 \mathrm{~K}$ & 0.188617 & 0.391208 & 49847 \\
\hline $25 \mathrm{~K}-49 \mathrm{~K}$ & 0.298554 & 0.457628 & 49847 \\
\hline $50 \mathrm{~K}-69 \mathrm{~K}$ & 0.187233 & 0.390102 & 49847 \\
\hline $70 \mathrm{~K}-99 \mathrm{~K}$ & 0.165326 & 0.371478 & 49847 \\
\hline $100 \mathrm{~K}+$ & 0.16027 & 0.36686 & 49847 \\
\hline HHSize $=1$ & 0.157181 & 0.363975 & 49847 \\
\hline HHSize $=2$ & 0.363091 & 0.480896 & 49847 \\
\hline HHSize $=3$ & 0.208839 & 0.406483 & 49847 \\
\hline HHSize $=4$ & 0.171425 & 0.376883 & 49847 \\
\hline HHSize $=5+$ & 0.099464 & 0.299288 & 49847 \\
\hline Age $<25$ & 0.091319 & 0.288066 & 49847 \\
\hline Age 25-34 & 0.162758 & 0.369149 & 49847 \\
\hline Age 35-44 & 0.196381 & 0.397264 & 49847 \\
\hline Age 45-54 & 0.221518 & 0.415272 & 49847 \\
\hline Age 55-64 & 0.170321 & 0.375919 & 49847 \\
\hline Age 65+ & 0.157703 & 0.364466 & 49847 \\
\hline
\end{tabular}


Table 1b

Summary Statistics 2008

\begin{tabular}{|c|c|c|c|}
\hline Variable & $\underline{\text { Mean }}$ & Std. Dev. & \# of Obs. \\
\hline Telephone & 0.901694 & 0.297731 & 47698 \\
\hline Television & 0.822529 & 0.382071 & 47698 \\
\hline Broadband & 0.61925 & 0.485576 & 47698 \\
\hline TelephoneCableCo & 0.141872 & 0.348922 & 47698 \\
\hline TelevisionCableCo & 0.530651 & 0.499065 & 47698 \\
\hline BroadbandCableCo & 0.290809 & 0.45414 & 47698 \\
\hline Bundle & 0.278649 & 0.448339 & 47698 \\
\hline All Three Services & 0.508197 & 0.499938 & 47698 \\
\hline Less Than H.S. & 0.063126 & 0.243193 & 47698 \\
\hline H.S. Degree & 0.260451 & 0.438885 & 47698 \\
\hline Some College & 0.336597 & 0.472551 & 47698 \\
\hline College Degree & 0.209191 & 0.406735 & 47698 \\
\hline Graduate Degree & 0.130634 & 0.337004 & 47698 \\
\hline$<25 \mathrm{~K}$ & 0.204055 & 0.403013 & 47698 \\
\hline $25 \mathrm{~K}-49 \mathrm{~K}$ & 0.277328 & 0.447685 & 47698 \\
\hline $50 \mathrm{~K}-69 \mathrm{~K}$ & 0.179483 & 0.383761 & 47698 \\
\hline $70 \mathrm{~K}-99 \mathrm{~K}$ & 0.159147 & 0.365817 & 47698 \\
\hline $100 \mathrm{~K}+$ & 0.179987 & 0.38418 & 47698 \\
\hline HHSize $=1$ & 0.171307 & 0.376781 & 47698 \\
\hline HHSize $=2$ & 0.368925 & 0.482519 & 47698 \\
\hline HHSize $=3$ & 0.203363 & 0.402504 & 47698 \\
\hline HHSize $=4$ & 0.161537 & 0.36803 & 47698 \\
\hline HHSize $=5+$ & 0.094868 & 0.293035 & 47698 \\
\hline Age $<25$ & 0.082268 & 0.274775 & 47698 \\
\hline Age 25-34 & 0.134974 & 0.3417 & 47698 \\
\hline Age 35-44 & 0.17898 & 0.38334 & 47698 \\
\hline Age 45-54 & 0.213699 & 0.409921 & 47698 \\
\hline Age 55-64 & 0.189652 & 0.392029 & 47698 \\
\hline Age 65+ & 0.200428 & 0.400325 & 47698 \\
\hline
\end{tabular}


Table 1c ${ }^{\underline{25}}$

Summary Statistics 2009

\begin{tabular}{|c|c|c|c|}
\hline Variable & $\underline{\text { Mean }}$ & $\underline{\text { Std. Dev. }}$ & \# of Obs. \\
\hline Telephone & 0.854976 & 0.35213 & 36194 \\
\hline Television & 0.773858 & 0.418338 & 36194 \\
\hline Broadband & 0.6784 & 0.467097 & 36194 \\
\hline TelephoneCableCo & 0.164613 & 0.370836 & 36194 \\
\hline TelevisionCableCo & 0.446704 & 0.497158 & 36194 \\
\hline BroadbandCableCo & 0.317843 & 0.465644 & 36194 \\
\hline Less Than H.S. & 0.062027 & 0.241208 & 36194 \\
\hline H.S. Degree & 0.249378 & 0.432659 & 36194 \\
\hline Some College & 0.330055 & 0.470239 & 36194 \\
\hline College Degree & 0.221307 & 0.415133 & 36194 \\
\hline Graduate Degree & 0.137233 & 0.344098 & 36194 \\
\hline$<25 \mathrm{~K}$ & 0.197408 & 0.398049 & 36194 \\
\hline $25 \mathrm{~K}-49 \mathrm{~K}$ & 0.260955 & 0.439161 & 36194 \\
\hline $50 \mathrm{~K}-69 \mathrm{~K}$ & 0.164641 & 0.370861 & 36194 \\
\hline $70 \mathrm{~K}-99 \mathrm{~K}$ & 0.174891 & 0.379879 & 36194 \\
\hline $100 \mathrm{~K}+$ & 0.202105 & 0.401576 & 36194 \\
\hline HHSize $=1$ & 0.161988 & 0.368445 & 36194 \\
\hline HHSize $=2$ & 0.343565 & 0.474905 & 36194 \\
\hline HHSize $=3$ & 0.20263 & 0.401965 & 36194 \\
\hline HHSize $=4$ & 0.177074 & 0.381736 & 36194 \\
\hline HHSize = 5+ & 0.114743 & 0.318716 & 36194 \\
\hline Age $<25$ & 0.093634 & 0.291323 & 36194 \\
\hline Age 25-34 & 0.160773 & 0.367326 & 36194 \\
\hline Age 35-44 & 0.196607 & 0.397438 & 36194 \\
\hline Age 45-54 & 0.19622 & 0.397143 & 36194 \\
\hline Age 55-64 & 0.174559 & 0.379595 & 36194 \\
\hline Age 65+ & 0.178206 & 0.382692 & 36194 \\
\hline
\end{tabular}

\footnotetext{
${ }^{25}$ We did not include the variable "Bundle" or "All Three Services" in this table because we did not use these
} variables for this year of data. 
Grouping at DMA, income, education, household size, and age level

$\underline{\text { Table 2a: 2007-2008 }}{ }^{26}$

\begin{tabular}{|c|c|c|c|c|c|c|}
\hline \multirow[t]{3}{*}{ Covariates } & \multicolumn{6}{|c|}{ Dependent Variable } \\
\hline & \multicolumn{2}{|c|}{ Telephone } & \multicolumn{2}{|c|}{ Television } & \multicolumn{2}{|c|}{ Broadband } \\
\hline & Coeff. & Std. Err. & Coeff. & Std. Err. & Coeff. & Std. Err. \\
\hline DepVarAvg $_{\mathrm{t}-1}$ & $0.184743^{* *}$ & 0.012256 & $0.169289 * *$ & 0.009366 & $0.161881^{* *}$ & 0.012196 \\
\hline BundleAvg $_{\mathrm{t}-1}$ & -0.00271 & 0.005634 & 0.005715 & 0.006959 & $0.015415^{+}$ & 0.008615 \\
\hline AllThreeAvg $g_{t-1}$ & -0.00083 & 0.004787 & -0.00572 & 0.006514 & -0.00442 & 0.011733 \\
\hline $\begin{array}{l}\text { Covariates for } \\
\text { DMA, income, } \\
\text { education, } \\
\text { household size, age }\end{array}$ & \multicolumn{2}{|c|}{ Yes } & \multicolumn{2}{|c|}{ Yes } & \multicolumn{2}{|c|}{ Yes } \\
\hline $\begin{array}{c}\text { DMA-level } \\
\text { Dummies }\end{array}$ & \multicolumn{2}{|c|}{ Yes } & \multicolumn{2}{|c|}{ Yes } & \multicolumn{2}{|c|}{ Yes } \\
\hline R-squared & \multicolumn{2}{|c|}{0.104} & \multicolumn{2}{|c|}{0.068} & \multicolumn{2}{|c|}{0.198} \\
\hline Observations & \multicolumn{2}{|c|}{34070} & \multicolumn{2}{|c|}{34070} & \multicolumn{2}{|c|}{34070} \\
\hline
\end{tabular}

Table 2b: 2007-2008

\begin{tabular}{|c|c|c|c|c|c|c|}
\hline Covariates & \multicolumn{6}{|c|}{ Dependent Variable } \\
\hline & \multicolumn{2}{|c|}{ TelephoneCableCo } & \multicolumn{2}{|c|}{ TelevisionCableCo } & \multicolumn{2}{|c|}{ BroadbandCableCo } \\
\hline & Coeff. & Std. Err. & Coeff. & Std. Err. & Coeff. & Std. Err. \\
\hline DepVarAvg $_{t-1}$ & $0.149843^{* *}$ & 0.012478 & $0.184701 * *$ & 0.0079 & $0.156389 * *$ & 0.009327 \\
\hline BundleAvg $g_{\mathrm{t}-1}$ & $0.013511+$ & 0.008183 & -0.0111 & 0.009751 & $0.022765 *$ & 0.009355 \\
\hline AllThreeAvg ${ }_{t-1}$ & 0.00414 & 0.005727 & -0.00444 & 0.008365 & 0.011664 & 0.007726 \\
\hline $\begin{array}{l}\text { Covariates for } \\
\text { DMA, income, } \\
\text { education, } \\
\text { household size, age }\end{array}$ & \multicolumn{2}{|c|}{ Yes } & \multicolumn{2}{|c|}{ Yes } & \multicolumn{2}{|c|}{ Yes } \\
\hline $\begin{array}{c}\text { DMA-level } \\
\text { Dummies }\end{array}$ & \multicolumn{2}{|c|}{ Yes } & \multicolumn{2}{|c|}{ Yes } & \multicolumn{2}{|c|}{ Yes } \\
\hline R-squared & \multicolumn{2}{|c|}{0.056} & \multicolumn{2}{|c|}{0.065} & \multicolumn{2}{|c|}{0.093} \\
\hline Observations & \multicolumn{2}{|c|}{34070} & \multicolumn{2}{|c|}{34070} & \multicolumn{2}{|c|}{34070} \\
\hline
\end{tabular}

\footnotetext{
$26 * *$ is significant at $1 \%$ level; * is significant at $5 \%$ level; + is significant at $10 \%$ level. Reported standard errors are robust to heteroskedasticity. Results change trivially when errors are clustered by DMA.
} 
Table 2c: 2008-2009 ${ }^{27}$

\begin{tabular}{|c|c|c|c|c|c|c|}
\hline Covariates & \multicolumn{6}{|c|}{ Dependent Variable } \\
\hline & \multicolumn{2}{|c|}{ Telephone } & \multicolumn{2}{|c|}{ Television } & \multicolumn{2}{|c|}{ Broadband } \\
\hline & Coeff. & Std. Err. & Coeff. & Std. Err. & Coeff. & Std. Err. \\
\hline DepVarAvg $_{t-1}$ & $0.256198^{* *}$ & 0.01344 & $0.201352 * *$ & 0.011716 & $0.22366 * *$ & 0.012296 \\
\hline BundleAvg t-1 $_{1}$ & 0.009231 & 0.006851 & $0.022288 * *$ & 0.007904 & 0.007229 & 0.00844 \\
\hline AllThreeAvg $\mathrm{t}_{\mathrm{t}-1}$ & -0.00521 & 0.006628 & $0.015384+$ & 0.008463 & $-0.02083+$ & 0.011121 \\
\hline $\begin{array}{l}\text { Covariates for } \\
\text { DMA, income, } \\
\text { education, } \\
\text { household size, age }\end{array}$ & \multicolumn{2}{|c|}{ Yes } & \multicolumn{2}{|c|}{ Yes } & \multicolumn{2}{|c|}{ Yes } \\
\hline $\begin{array}{c}\text { DMA-level } \\
\text { Dummies }\end{array}$ & \multicolumn{2}{|c|}{ Yes } & \multicolumn{2}{|c|}{ Yes } & \multicolumn{2}{|c|}{ Yes } \\
\hline R-squared & \multicolumn{2}{|c|}{0.140} & \multicolumn{2}{|c|}{0.083} & \multicolumn{2}{|c|}{0.239} \\
\hline Observations & \multicolumn{2}{|c|}{25668} & \multicolumn{2}{|c|}{25668} & \multicolumn{2}{|c|}{25668} \\
\hline
\end{tabular}

Table 2d: 2008-2009

\begin{tabular}{|c|c|c|c|c|c|c|}
\hline \multirow[t]{3}{*}{$\underline{\text { Covariates }}$} & \multicolumn{6}{|c|}{ Dependent Variable } \\
\hline & \multicolumn{2}{|c|}{ TelephoneCableCo } & \multicolumn{2}{|c|}{ TelevisionCableCo } & \multicolumn{2}{|c|}{ BroadbandCableCo } \\
\hline & Coeff. & "Std. Err. & $\overline{\text { Coeff. }}$ & " Std. Err. & $\overline{\text { Coeff. }}$ & "Std. Err. \\
\hline DepVarAvg $_{\mathrm{t}-1}$ & $0.183547^{* *}$ & 0.012094 & $0.203363^{* *}$ & 0.008644 & $0.201266 * *$ & 0.00975 \\
\hline BundleAvg $_{\mathrm{t}-1}$ & $0.035604^{* *}$ & 0.00851 & $0.022013^{*}$ & 0.010114 & 0.005973 & 0.009715 \\
\hline AllThreeAvg ${ }_{t-1}$ & 0.005201 & 0.006747 & 0.00017 & 0.009462 & 0.007187 & 0.00869 \\
\hline $\begin{array}{l}\text { Covariates for } \\
\text { DMA, income, } \\
\text { education, } \\
\text { household size, age }\end{array}$ & \multicolumn{2}{|c|}{ Yes } & \multicolumn{2}{|c|}{ Yes } & \multicolumn{2}{|c|}{ Yes } \\
\hline $\begin{array}{c}\text { DMA-level } \\
\text { Dummies }\end{array}$ & \multicolumn{2}{|c|}{ Yes } & \multicolumn{2}{|c|}{ Yes } & \multicolumn{2}{|c|}{ Yes } \\
\hline R-squared & \multicolumn{2}{|c|}{0.073} & \multicolumn{2}{|c|}{0.075} & \multicolumn{2}{|c|}{0.115} \\
\hline Observations & \multicolumn{2}{|c|}{25668} & \multicolumn{2}{|c|}{25668} & \multicolumn{2}{|c|}{25668} \\
\hline
\end{tabular}

$27 * *$ is significant at $1 \%$ level; * is significant at $5 \%$ level; + is significant at $10 \%$ level. Reported standard errors are robust to heteroskedasticity. Results change trivially when errors are clustered by DMA. 
Nearest Neighbor by DMA, income, education, household size, and age level

Table 3a: 2007-2008

\begin{tabular}{|c|c|c|c|c|c|c|}
\hline \multirow[t]{3}{*}{ Covariates } & \multicolumn{6}{|c|}{ Dependent Variable } \\
\hline & \multicolumn{2}{|c|}{ Telephone } & \multicolumn{2}{|c|}{ Television } & \multicolumn{2}{|c|}{ Broadband } \\
\hline & Coeff. & Std. Err. & Coeff. & Std. Err. & Coeff. & $\overline{\text { Std. Err. }}$ \\
\hline $\operatorname{DepVar}_{\mathrm{t}-1}$ & $0.083544 * *$ & 0.005228 & $0.068013^{* *}$ & 0.005124 & $0.067105 * *$ & 0.007489 \\
\hline Bundle $_{\mathrm{t}-1}$ & -0.00159 & 0.003332 & 0.001374 & 0.004367 & 0.008327 & 0.005189 \\
\hline AllThree $_{t-1}$ & 0.000666 & 0.003005 & 0.002109 & 0.00412 & -0.00672 & 0.007369 \\
\hline $\begin{array}{l}\text { Covariates for } \\
\text { DMA, income, } \\
\text { education, } \\
\text { household size, age }\end{array}$ & \multicolumn{2}{|c|}{ Yes } & \multicolumn{2}{|c|}{ Yes } & \multicolumn{2}{|c|}{ Yes } \\
\hline $\begin{array}{l}\text { DMA-level } \\
\text { Dummies }\end{array}$ & \multicolumn{2}{|c|}{ Yes } & \multicolumn{2}{|c|}{ Yes } & \multicolumn{2}{|c|}{ Yes } \\
\hline R-squared & \multicolumn{2}{|c|}{0.095} & \multicolumn{2}{|c|}{0.057} & \multicolumn{2}{|c|}{0.176} \\
\hline Observations & \multicolumn{2}{|c|}{47698} & \multicolumn{2}{|c|}{47698} & \multicolumn{2}{|c|}{47698} \\
\hline
\end{tabular}

Table 3b: 2007-2008

\begin{tabular}{|c|c|c|c|c|c|c|}
\hline \multirow[t]{3}{*}{ Covariates } & \multicolumn{6}{|c|}{ Dependent Variable } \\
\hline & \multicolumn{2}{|c|}{ TelephoneCableCo } & \multicolumn{2}{|c|}{ TelevisionCableCo } & \multicolumn{2}{|c|}{ BroadbandCableCo } \\
\hline & Coeff. & Std. Err. & Coeff. & Std. Err. & Coeff. & Std. Err. \\
\hline DepVar $_{\mathrm{t}-1}$ & $0.056902 * *$ & 0.006238 & $0.072685 * *$ & 0.004751 & $0.062294 * *$ & 0.005181 \\
\hline Bundle $_{\mathrm{t}-1}$ & 0.004778 & 0.004703 & -0.00243 & 0.005717 & $0.008903+$ & 0.005181 \\
\hline AllThree $_{\mathrm{t}-1}$ & 0.004626 & 0.003488 & -7.3E-05 & 0.005081 & 0.007473 & 0.004644 \\
\hline $\begin{array}{l}\text { Covariates for } \\
\text { DMA, income, } \\
\text { education, } \\
\text { household size, age }\end{array}$ & \multicolumn{2}{|c|}{ Yes } & \multicolumn{2}{|c|}{ Yes } & \multicolumn{2}{|c|}{ Yes } \\
\hline $\begin{array}{l}\text { DMA-level } \\
\text { Dummies }\end{array}$ & \multicolumn{2}{|c|}{ Yes } & \multicolumn{2}{|c|}{ Yes } & \multicolumn{2}{|c|}{ Yes } \\
\hline R-squared & \multicolumn{2}{|c|}{0.047} & \multicolumn{2}{|c|}{0.054} & \multicolumn{2}{|c|}{0.083} \\
\hline Observations & \multicolumn{2}{|c|}{47698} & \multicolumn{2}{|c|}{47698} & \multicolumn{2}{|c|}{47698} \\
\hline
\end{tabular}

$28 * *$ is significant at $1 \%$ level; * is significant at $5 \%$ level; + is significant at $10 \%$ level. Reported standard errors are robust to heteroskedasticity. Results change trivially when errors are clustered by DMA. 
Table 3c: 2008-2009 $\underline{29}$

\begin{tabular}{|c|c|c|c|c|c|c|}
\hline Covariates & \multicolumn{6}{|c|}{ Dependent Variable } \\
\hline & \multicolumn{2}{|c|}{ Telephone } & \multicolumn{2}{|c|}{ Television } & \multicolumn{2}{|c|}{ Broadband } \\
\hline & Coeff. & Std. Err. & Coeff. & Std. Err. & Coeff. & Std. Err. \\
\hline DepVar $_{\mathrm{t}-1}$ & $0.117952 * *$ & 0.006447 & $0.087545 * *$ & 0.006561 & $0.094963 * *$ & 0.007817 \\
\hline Bundle $_{t-1}$ & 0.001478 & 0.004201 & 0.006919 & 0.005178 & 0.002114 & 0.005292 \\
\hline AllThree $_{t-1}$ & -0.00239 & 0.004247 & 0.008331 & 0.005361 & -0.0065 & 0.007475 \\
\hline $\begin{array}{c}\text { Covariates for } \\
\text { DMA, income, } \\
\text { education, } \\
\text { household size, age }\end{array}$ & \multicolumn{2}{|c|}{ Yes } & \multicolumn{2}{|c|}{ Yes } & \multicolumn{2}{|c|}{ Yes } \\
\hline $\begin{array}{c}\text { DMA-level } \\
\text { Dummies }\end{array}$ & \multicolumn{2}{|c|}{ Yes } & \multicolumn{2}{|c|}{ Yes } & \multicolumn{2}{|c|}{ Yes } \\
\hline R-squared & \multicolumn{2}{|c|}{0.123} & \multicolumn{2}{|c|}{0.066} & \multicolumn{2}{|c|}{0.209} \\
\hline Observations & \multicolumn{2}{|c|}{36194} & \multicolumn{2}{|c|}{36194} & \multicolumn{2}{|c|}{36194} \\
\hline
\end{tabular}

Table 3d: 2008-2009

\begin{tabular}{|c|c|c|c|c|c|c|}
\hline Covariates & \multicolumn{6}{|c|}{ Dependent Variable } \\
\hline & \multicolumn{2}{|c|}{ TelephoneCableCo } & \multicolumn{2}{|c|}{ TelevisionCableCo } & \multicolumn{2}{|c|}{ BroadbandCableCo } \\
\hline & Coeff. & Std. Err. & Coeff. & " Std. Err. & Coeff. & "Std. Err. \\
\hline DepVar $_{t-1}$ & $0.084987 * *$ & 0.006466 & $0.087571^{* *}$ & 0.005424 & $0.086076^{* *}$ & 0.005726 \\
\hline Bundle $_{\mathrm{t}-1}$ & $0.01531^{* *}$ & 0.005231 & 0.009568 & 0.006187 & 0.005879 & 0.005818 \\
\hline AllThree $_{t-1}$ & -0.00023 & 0.004363 & 0.003065 & 0.005935 & 0.002774 & 0.005461 \\
\hline $\begin{array}{l}\text { Covariates for } \\
\text { DMA, income, } \\
\text { education, } \\
\text { household size, age }\end{array}$ & \multicolumn{2}{|c|}{ Yes } & \multicolumn{2}{|c|}{ Yes } & \multicolumn{2}{|c|}{ Yes } \\
\hline $\begin{array}{c}\text { DMA-level } \\
\text { Dummies }\end{array}$ & \multicolumn{2}{|c|}{ Yes } & \multicolumn{2}{|c|}{ Yes } & \multicolumn{2}{|c|}{ Yes } \\
\hline R-squared & \multicolumn{2}{|c|}{0.057} & \multicolumn{2}{|c|}{0.058} & \multicolumn{2}{|c|}{0.097} \\
\hline Observations & \multicolumn{2}{|c|}{36194} & \multicolumn{2}{|c|}{36194} & \multicolumn{2}{|c|}{36194} \\
\hline
\end{tabular}

$29 * *$ is significant at $1 \%$ level; * is significant at $5 \%$ level; + is significant at $10 \%$ level. Reported standard errors are robust to heteroskedasticity. Results change trivially when errors are clustered by DMA. 


\section{Table 4}

Service adoption levels by year

\begin{tabular}{|c|c|c|}
\hline Variable & Year & Adoption Rate \\
\hline Telephone & 2007 & 0.9080 \\
\hline & 2008 & 0.9017 \\
\hline & 2009 & 0.8550 \\
\hline Television & 2007 & 0.8284 \\
\hline & 2008 & 0.8225 \\
\hline & 2009 & 0.7739 \\
\hline Broadband & 2007 & 0.5939 \\
\hline & 2008 & 0.6193 \\
\hline & 2009 & 0.6784 \\
\hline TelephoneCableCo & 2007 & 0.1052 \\
\hline & 2008 & 0.1419 \\
\hline & 2009 & 0.1646 \\
\hline TelevisionCableCo & 2007 & 0.5380 \\
\hline & 2008 & 0.5307 \\
\hline & 2009 & 0.4467 \\
\hline BroadbandCableCo & 2007 & 0.2538 \\
\hline & 2008 & 0.2908 \\
\hline & 2009 & 0.3178 \\
\hline
\end{tabular}


Table 5

Proportions of households with all possible broadband and (pay) television service combinations

\begin{tabular}{|c|c|c|c|c|}
\hline Year & TV \& Broadband & TV \& No & $\begin{array}{l}\text { No TV \& } \\
\text { Broadband }\end{array}$ & $\begin{array}{l}\text { No TV \& No } \\
\text { Broadband }\end{array}$ \\
\hline 2007 & 0.4945 & 0.3084 & 0.0664 & 0.1307 \\
\hline 2008 & 0.5399 & 0.2785 & 0.0650 & 0.1165 \\
\hline 2009 & 0.5325 & 0.2167 & 0.1175 & 0.1334 \\
\hline
\end{tabular}

\section{Table $\underline{30}^{30}$}

Relationship between having broadband and no (pay) television and key demographics

\begin{tabular}{|c|c|c|c|c|c|c|}
\hline \multirow{2}{*}{$\begin{array}{c}\frac{\text { Dep. Var.: }}{\text { Broadband \& }} \\
\underline{\text { No TV }}\end{array}$} & \multicolumn{2}{|c|}{$\underline{2007}$} & \multicolumn{2}{|c|}{$\underline{2008}$} & \multicolumn{2}{|c|}{$\underline{2009}$} \\
\hline & Coeff. & Std. Err. & Coeff. & Std. Err. & Coeff. & Std. Err. \\
\hline Age 25-34 & $-0.02684 * *$ & 0.004272 & $-0.02571^{* *}$ & 0.004739 & $-0.0537 * *$ & 0.006529 \\
\hline Age 35-44 & $-0.04743 * *$ & 0.004139 & $-0.04394 * *$ & 0.00452 & $-0.07195^{* *}$ & 0.006301 \\
\hline Age 45-54 & $-0.0486 * *$ & 0.004088 & $-0.04731^{* *}$ & 0.004444 & $-0.08718 * *$ & 0.006312 \\
\hline Age 55-64 & $-0.05936^{* *}$ & 0.004384 & $-0.06029 * *$ & 0.004667 & $-0.10691 * *$ & 0.006669 \\
\hline Age 65+ & $-0.06793 * *$ & 0.004431 & $-0.07181^{* *}$ & 0.004719 & $-0.1241 * *$ & 0.006766 \\
\hline $25 \mathrm{~K}-49 \mathrm{~K}$ & $-0.00669 *$ & 0.003027 & -0.00139 & 0.003176 & 0.003888 & 0.004705 \\
\hline $50 \mathrm{~K}-69 \mathrm{~K}$ & $-0.01142 * *$ & 0.003472 & $-0.00766^{*}$ & 0.003625 & -0.00539 & 0.005428 \\
\hline $70 \mathrm{~K}-99 \mathrm{~K}$ & $-0.0173 * *$ & 0.00369 & $-0.01276 * *$ & 0.003835 & $-0.02348^{* *}$ & 0.005525 \\
\hline $100 \mathrm{~K}+$ & $-0.03333 * *$ & 0.003929 & $-0.02235^{* *}$ & 0.003958 & $-0.0318 * *$ & 0.005636 \\
\hline H.S. Degree & $0.009667 *$ & 0.004398 & 0.001303 & 0.004546 & $0.019587 * *$ & 0.006688 \\
\hline Some College & $0.029969 * *$ & 0.004353 & $0.027016^{* *}$ & 0.004509 & $0.048667 * *$ & 0.006634 \\
\hline $\begin{array}{l}\text { College } \\
\text { Degree }\end{array}$ & $0.053895^{* *}$ & 0.004725 & $0.047302 * *$ & 0.004908 & $0.072536^{* *}$ & 0.007191 \\
\hline $\begin{array}{c}\text { Graduate } \\
\text { Degree }\end{array}$ & $0.068672 * *$ & 0.005073 & $0.057847 * *$ & 0.005334 & $0.085964^{* *}$ & 0.007773 \\
\hline HHSize $=2$ & -0.00168 & 0.003096 & $-0.00735 *$ & 0.003186 & $-0.01151^{*}$ & 0.004752 \\
\hline HHSize $=3$ & -0.00212 & 0.003589 & $-0.01064 * *$ & 0.003748 & $-0.01954^{* *}$ & 0.005495 \\
\hline HHSize $=4$ & $0.01185 * *$ & 0.003851 & 0.002673 & 0.004061 & -0.00612 & 0.00584 \\
\hline HHSize $=5+$ & $0.037211^{* *}$ & 0.0044 & $0.027081^{* *}$ & 0.004643 & $0.019868 * *$ & 0.006482 \\
\hline Constant & $0.087547 * *$ & 0.005805 & $0.095941 * *$ & 0.006195 & $0.167391^{* *}$ & 0.00892 \\
\hline R-squared & \multicolumn{2}{|c|}{0.017} & \multicolumn{2}{|c|}{0.016} & \multicolumn{2}{|c|}{0.021} \\
\hline Observations & \multicolumn{2}{|c|}{59368} & \multicolumn{2}{|c|}{52765} & \multicolumn{2}{|c|}{41580} \\
\hline
\end{tabular}

$30 * *$ is significant at $1 \%$ level; * is significant at $5 \%$ level; + is significant at $10 \%$ level. 


\section{Table 7}

Demographics for bundlers and non-bundlers (with all three services) by year

\begin{tabular}{|c|c|c|c|c|}
\hline Year & Variable & $\begin{array}{c}\text { Mean for } \\
\text { Bundlers }\end{array}$ & $\begin{array}{c}\text { Mean for Non- } \\
\text { Bundlers with all } \\
\text { 3 services }\end{array}$ & $\begin{array}{c}\text { Different at 5\% } \\
\text { level? }\end{array}$ \\
\hline $\mathbf{2 0 0 7}$ & Income & 3.034 & 3.197 & Yes \\
\hline & Education & 3.199 & 3.297 & Yes \\
\hline & Age & 3.542 & 3.654 & Yes \\
\hline & Household Size & 2.821 & 2.785 & Yes \\
\hline $\mathbf{2 0 0 8}$ & Income & 3.106 & 3.207 & Yes \\
\hline & Education & 3.177 & 3.254 & Yes \\
\hline & Age & 3.835 & 3.847 & No \\
\hline & Household Size & 2.745 & 2.725 & No \\
\hline
\end{tabular}




\section{Appendix: Full results}

Table $2 \mathbf{a}^{31}$

2007-2008: Grouping at DMA, income, education, household size, and age level

\begin{tabular}{|c|c|c|c|c|c|c|}
\hline Covariates & \multicolumn{6}{|c|}{ Dependent Variable } \\
\hline & \multicolumn{2}{|c|}{ Telephone } & \multicolumn{2}{|c|}{ Television } & \multicolumn{2}{|c|}{ Broadband } \\
\hline & Coeff. & Std. Err. & Coeff. & Std. Err. & Coeff. & Std. Err. \\
\hline DepVarAvg $_{t-1}$ & $0.184743^{* *}$ & 0.012256 & $0.169289 * *$ & 0.009366 & $0.161881^{* *}$ & 0.012196 \\
\hline BundleAvg $_{\mathrm{t}-1}$ & -0.00271 & 0.005634 & 0.005715 & 0.006959 & $0.015415+$ & 0.008615 \\
\hline AllThreeAvg $g_{t-1}$ & -0.00083 & 0.004787 & -0.00572 & 0.006514 & -0.00442 & 0.011733 \\
\hline H.S. Degree & $0.031639 * *$ & 0.008357 & $0.030035^{*}$ & 0.012122 & $0.052206^{* *}$ & 0.012314 \\
\hline Some College & $0.026716^{* *}$ & 0.008534 & $0.024572 *$ & 0.012169 & $0.115226^{* *}$ & 0.012543 \\
\hline $\begin{array}{l}\text { College } \\
\text { Degree }\end{array}$ & $0.025871^{* *}$ & 0.008909 & $0.021586+$ & 0.012777 & $0.161089 * *$ & 0.013365 \\
\hline $\begin{array}{l}\text { Graduate } \\
\text { Degree }\end{array}$ & $0.02432 * *$ & 0.009052 & 0.005992 & 0.013244 & $0.182179 * *$ & 0.013965 \\
\hline $25 \mathrm{~K}-49 \mathrm{~K}$ & $0.013615^{* *}$ & 0.005179 & $0.076249 * *$ & 0.007249 & $0.11976 * *$ & 0.007983 \\
\hline $50 \mathrm{~K}-69 \mathrm{~K}$ & $0.020832 * *$ & 0.005788 & $0.111985^{* *}$ & 0.007993 & $0.205497^{* *}$ & 0.009202 \\
\hline $70 \mathrm{~K}-99 \mathrm{~K}$ & $0.032056 * *$ & 0.005938 & $0.127622^{* *}$ & 0.008338 & $0.254535^{* *}$ & 0.009659 \\
\hline $100 \mathrm{~K}+$ & $0.032817 * *$ & 0.005794 & $0.15292 * *$ & 0.008387 & $0.305286^{* *}$ & 0.009811 \\
\hline HHSize $=2$ & $0.028015^{* *}$ & 0.004561 & $0.054422 * *$ & 0.006802 & $0.057711 * *$ & 0.007463 \\
\hline HHSize $=3$ & $0.049931^{* *}$ & 0.005978 & $0.060279 * *$ & 0.007858 & $0.067071^{* *}$ & 0.009063 \\
\hline HHSize $=4$ & $0.065887^{* *}$ & 0.006633 & $0.046224^{* *}$ & 0.008548 & $0.094256^{* *}$ & 0.009629 \\
\hline HHSize = 5+ & $0.063574^{* *}$ & 0.007757 & 0.00486 & 0.01059 & $0.072062 * *$ & 0.01158 \\
\hline Age 25-34 & 0.016397 & 0.010837 & $0.055796 * *$ & 0.01085 & $0.029378^{*}$ & 0.011891 \\
\hline Age $35-44$ & $0.103589 * *$ & 0.009816 & $0.067976^{* *}$ & 0.010288 & -0.00351 & 0.011372 \\
\hline Age 45-54 & $0.142697 * *$ & 0.009536 & $0.063159 * *$ & 0.010154 & $-0.03987 * *$ & 0.011294 \\
\hline Age 55-64 & $0.172129 * *$ & 0.009792 & $0.07209 * *$ & 0.010614 & $-0.06938^{* *}$ & 0.012044 \\
\hline Age 65+ & $0.202174^{* *}$ & 0.009896 & $0.054361^{* *}$ & 0.010956 & $-0.18477 * *$ & 0.012391 \\
\hline Constant & $0.5379416^{* *}$ & 0.0570953 & $0.41688 * *$ & 0.0987719 & $0.1745673+$ & 0.1033812 \\
\hline $\begin{array}{c}\text { DMA-level } \\
\text { Dummies }\end{array}$ & \multicolumn{2}{|c|}{ Yes } & \multicolumn{2}{|c|}{ Yes } & \multicolumn{2}{|c|}{ Yes } \\
\hline R-squared & \multicolumn{2}{|c|}{0.104} & \multicolumn{2}{|c|}{0.068} & \multicolumn{2}{|c|}{0.198} \\
\hline Observations & \multicolumn{2}{|c|}{34070} & \multicolumn{2}{|c|}{34070} & \multicolumn{2}{|c|}{34070} \\
\hline
\end{tabular}

\footnotetext{
31 ** is significant at $1 \%$ level; * is significant at $5 \%$ level; + is significant at $10 \%$ level. Reported standard errors
} are robust to heteroskedasticity. Results change trivially when errors are clustered by DMA. 
Table $2 \mathbf{b}^{32}$

2007-2008: Grouping at DMA, income, education, household size, and age level

\begin{tabular}{|c|c|c|c|c|c|c|}
\hline \multirow[t]{3}{*}{ Covariates } & \multicolumn{6}{|c|}{ Dependent Variable } \\
\hline & \multicolumn{2}{|c|}{ TelephoneCableCo } & \multicolumn{2}{|c|}{ TelevisionCableCo } & \multicolumn{2}{|c|}{ BroadbandCableCo } \\
\hline & Coeff. & Std. Err. & Coeff. & Std. Err. & Coeff. & Std. Err. \\
\hline DepVarAvg $g_{t-1}$ & $0.149843^{* *}$ & 0.012478 & $0.184701 * *$ & 0.0079 & $0.156389 * *$ & 0.009327 \\
\hline BundleAvg $_{\mathrm{t}-1}$ & $0.013511+$ & 0.008183 & -0.0111 & 0.009751 & $0.022765 *$ & 0.009355 \\
\hline AllThreeAvg ${ }_{t-1}$ & 0.00414 & 0.005727 & -0.00444 & 0.008365 & 0.011664 & 0.007726 \\
\hline H.S. Degree & 0.001801 & 0.008936 & 0.021702 & 0.013916 & 0.014059 & 0.009877 \\
\hline Some College & 0.004216 & 0.009014 & $0.026383+$ & 0.014011 & $0.042288 * *$ & 0.010164 \\
\hline $\begin{array}{l}\text { College } \\
\text { Degree }\end{array}$ & 0.005141 & 0.009834 & $0.046399 * *$ & 0.014942 & $0.058298 * *$ & 0.011361 \\
\hline $\begin{array}{l}\text { Graduate } \\
\text { Degree }\end{array}$ & -0.0158 & 0.010445 & $0.044881^{* *}$ & 0.015779 & $0.056733 * *$ & 0.012398 \\
\hline $25 \mathrm{~K}-49 \mathrm{~K}$ & $0.012686^{*}$ & 0.005374 & $0.024823^{* *}$ & 0.008346 & $0.054894 * *$ & 0.006607 \\
\hline $50 \mathrm{~K}-69 \mathrm{~K}$ & $0.023149 * *$ & 0.006571 & $0.044237^{* *}$ & 0.009697 & $0.091858 * *$ & 0.008202 \\
\hline $70 \mathrm{~K}-99 \mathrm{~K}$ & $0.037721^{* *}$ & 0.007287 & $0.055509 * *$ & 0.01043 & $0.122394 * *$ & 0.009099 \\
\hline $100 \mathrm{~K}+$ & $0.037279 * *$ & 0.00751 & $0.08036^{* *}$ & 0.010693 & $0.163272^{* *}$ & 0.009487 \\
\hline HHSize $=2$ & $0.022957^{* *}$ & 0.005263 & -0.00421 & 0.008086 & $0.023943 * *$ & 0.006643 \\
\hline HHSize $=3$ & $0.039052 * *$ & 0.006717 & 0.004533 & 0.009858 & $0.036446 * *$ & 0.008621 \\
\hline HHSize $=4$ & $0.0428 * *$ & 0.007508 & $-0.02325^{*}$ & 0.0108 & $0.036856 * *$ & 0.009653 \\
\hline HHSize $=5+$ & $0.043541^{* *}$ & 0.009078 & $-0.03784 * *$ & 0.012684 & $0.033802 * *$ & 0.011519 \\
\hline Age 25-34 & $0.022538^{*}$ & 0.008961 & -0.00984 & 0.013049 & 0.012159 & 0.0125 \\
\hline Age 35-44 & $0.036501^{* *}$ & 0.008649 & -0.00214 & 0.012398 & $-0.02818^{*}$ & 0.011826 \\
\hline Age 45-54 & $0.030252^{* *}$ & 0.008479 & 0.005838 & 0.012205 & $-0.0471^{* *}$ & 0.011627 \\
\hline Age 55-64 & $0.038982 * *$ & 0.009026 & 0.01005 & 0.012941 & $-0.06467 * *$ & 0.012229 \\
\hline Age 65+ & $0.024735^{* *}$ & 0.008981 & 0.009298 & 0.013117 & $-0.10362 * *$ & 0.012196 \\
\hline Constant & 0.0486289 & 0.074471 & $0.1696456+$ & 0.1027844 & $0.2610282 *$ & 0.1035324 \\
\hline $\begin{array}{c}\text { DMA-level } \\
\text { Dummies }\end{array}$ & \multicolumn{2}{|c|}{ Yes } & \multicolumn{2}{|c|}{ Yes } & \multicolumn{2}{|c|}{ Yes } \\
\hline R-squared & \multicolumn{2}{|c|}{0.056} & \multicolumn{2}{|c|}{0.065} & \multicolumn{2}{|c|}{0.093} \\
\hline Observations & \multicolumn{2}{|c|}{34070} & \multicolumn{2}{|c|}{34070} & \multicolumn{2}{|c|}{34070} \\
\hline
\end{tabular}

$32 * *$ is significant at $1 \%$ level; * is significant at $5 \%$ level; + is significant at $10 \%$ level. Reported standard errors are robust to heteroskedasticity. Results change trivially when errors are clustered by DMA. 
Table $2 c^{33}$

2008-2009: Grouping at DMA, income, education, household size, and age level

\begin{tabular}{|c|c|c|c|c|c|c|}
\hline Covariates & \multicolumn{6}{|c|}{ Dependent Variable } \\
\hline & \multicolumn{2}{|c|}{ Telephone } & \multicolumn{2}{|c|}{ Television } & \multicolumn{2}{|c|}{ Broadband } \\
\hline & Coeff. & Std. Err. & Coeff. & Std. Err. & Coeff. & Std. Err. \\
\hline DepVarAvg $g_{t-1}$ & $0.256198 * *$ & 0.01344 & $0.201352 * *$ & 0.011716 & $0.22366 * *$ & 0.012296 \\
\hline BundleAvg $_{\mathrm{t}-1}$ & 0.009231 & 0.006851 & $0.022288^{* *}$ & 0.007904 & 0.007229 & 0.00844 \\
\hline AllThreeAvg $_{\mathrm{t}-1}$ & -0.00521 & 0.006628 & $0.015384+$ & 0.008463 & $-0.02083+$ & 0.011121 \\
\hline H.S. Degree & 0.01118 & 0.009937 & $0.05857 * *$ & 0.014794 & $0.128468 * *$ & 0.013283 \\
\hline Some College & 0.003499 & 0.010262 & $0.071719 * *$ & 0.014866 & $0.239823^{* *}$ & 0.013571 \\
\hline $\begin{array}{l}\text { College } \\
\text { Degree }\end{array}$ & -0.00456 & 0.010855 & $0.059982 * *$ & 0.015578 & $0.288146^{* *}$ & 0.014347 \\
\hline $\begin{array}{l}\text { Graduate } \\
\text { Degree }\end{array}$ & -0.00242 & 0.011231 & $0.057642 * *$ & 0.016173 & $0.282492 * *$ & 0.015009 \\
\hline $25 \mathrm{~K}-49 \mathrm{~K}$ & 0.006884 & 0.006814 & $0.080198^{* *}$ & 0.008895 & $0.112681^{* *}$ & 0.009138 \\
\hline $50 \mathrm{~K}-69 \mathrm{~K}$ & $0.028871^{* *}$ & 0.007734 & $0.110918 * *$ & 0.010002 & $0.165686^{* *}$ & 0.010477 \\
\hline $70 \mathrm{~K}-99 \mathrm{~K}$ & $0.036531^{* *}$ & 0.007825 & $0.142516^{* *}$ & 0.010034 & $0.204497^{* *}$ & 0.010642 \\
\hline $100 \mathrm{~K}+$ & $0.042331^{* *}$ & 0.007733 & $0.15639 * *$ & 0.010199 & $0.24983^{* *}$ & 0.010749 \\
\hline HHSize $=2$ & $0.030155^{* *}$ & 0.00607 & $0.061682 * *$ & 0.008299 & $0.051536 * *$ & 0.008282 \\
\hline HHSize $=3$ & $0.046956^{* *}$ & 0.007505 & $0.059547 * *$ & 0.009485 & $0.037436 * *$ & 0.009673 \\
\hline HHSize $=4$ & $0.065903 * *$ & 0.008208 & $0.053327 * *$ & 0.010114 & $0.059488 * *$ & 0.010111 \\
\hline HHSize $=5+$ & $0.067494 * *$ & 0.009701 & $0.023397+$ & 0.01209 & $0.058173^{* *}$ & 0.011795 \\
\hline Age 25-34 & 0.001823 & 0.013037 & $0.085986^{* *}$ & 0.013079 & $0.029311^{*}$ & 0.012311 \\
\hline Age 35-44 & $0.123842^{* *}$ & 0.011896 & $0.082094^{* *}$ & 0.012469 & 0.005295 & 0.01177 \\
\hline Age 45-54 & $0.169557^{* *}$ & 0.011659 & $0.091013^{* *}$ & 0.012448 & $-0.04066^{* *}$ & 0.011965 \\
\hline Age 55-64 & $0.198619 * *$ & 0.011975 & $0.104818^{* *}$ & 0.012951 & $-0.08148 * *$ & 0.012723 \\
\hline Age 65+ & $0.236294^{* *}$ & 0.012047 & $0.083198^{* *}$ & 0.013348 & $-0.17468 * *$ & 0.013301 \\
\hline Constant & $0.4127478^{* *}$ & 0.1169038 & $0.4244421^{* *}$ & 0.1343661 & 0.0476034 & 0.1340459 \\
\hline $\begin{array}{c}\text { DMA-level } \\
\text { Dummies }\end{array}$ & \multicolumn{2}{|c|}{ Yes } & \multicolumn{2}{|c|}{ Yes } & \multicolumn{2}{|c|}{ Yes } \\
\hline R-squared & \multicolumn{2}{|c|}{0.140} & \multicolumn{2}{|c|}{0.083} & \multicolumn{2}{|c|}{0.239} \\
\hline Observations & \multicolumn{2}{|c|}{25668} & \multicolumn{2}{|c|}{25668} & \multicolumn{2}{|c|}{25668} \\
\hline
\end{tabular}

\footnotetext{
33 ** is significant at $1 \%$ level; * is significant at $5 \%$ level; + is significant at $10 \%$ level. Reported standard errors
} are robust to heteroskedasticity. Results change trivially when errors are clustered by DMA. 
Table $2 \mathbf{d}^{34}$

2008-2009: Grouping at DMA, income, education, household size, and age level

\begin{tabular}{|c|c|c|c|c|c|c|}
\hline \multirow[t]{3}{*}{ Covariates } & \multicolumn{6}{|c|}{ Dependent Variable } \\
\hline & \multicolumn{2}{|c|}{ TelephoneCableCo } & \multicolumn{2}{|c|}{ TelevisionCableCo } & \multicolumn{2}{|c|}{ BroadbandCableCo } \\
\hline & Coeff. & Std. Err. & Coeff. & Std. Err. & Coeff. & Std. Err. \\
\hline DepVarAvg $g_{t-1}$ & $0.183547 * *$ & 0.012094 & $0.203363 * *$ & 0.008644 & $0.201266 * *$ & 0.00975 \\
\hline BundleAvg $_{\mathrm{t}-1}$ & $0.035604 * *$ & 0.00851 & $0.022013^{*}$ & 0.010114 & 0.005973 & 0.009715 \\
\hline AllThreeAvg $_{\mathrm{t}-1}$ & 0.005201 & 0.006747 & 0.00017 & 0.009462 & 0.007187 & 0.00869 \\
\hline H.S. Degree & 0.002358 & 0.010975 & $0.056671^{* *}$ & 0.014957 & $0.044154 * *$ & 0.010512 \\
\hline Some College & 0.00457 & 0.011123 & $0.066241^{* *}$ & 0.015154 & $0.084625^{* *}$ & 0.010981 \\
\hline $\begin{array}{l}\text { College } \\
\text { Degree }\end{array}$ & -0.00849 & 0.011991 & $0.082266^{* *}$ & 0.016289 & $0.126751^{* *}$ & 0.012471 \\
\hline $\begin{array}{l}\text { Graduate } \\
\text { Degree }\end{array}$ & -0.00989 & 0.012879 & $0.09468 * *$ & 0.017367 & $0.133533 * *$ & 0.01382 \\
\hline $25 \mathrm{~K}-49 \mathrm{~K}$ & $0.015356^{*}$ & 0.006643 & $0.030458 * *$ & 0.009483 & $0.050205^{* *}$ & 0.007782 \\
\hline $50 \mathrm{~K}-69 \mathrm{~K}$ & 0.019491* & 0.008068 & $0.046574^{* *}$ & 0.011185 & $0.077969 * *$ & 0.009748 \\
\hline $70 \mathrm{~K}-99 \mathrm{~K}$ & $0.043207 * *$ & 0.008617 & $0.068655^{* *}$ & 0.011641 & $0.116049 * *$ & 0.010325 \\
\hline $100 \mathrm{~K}+$ & $0.041545^{* *}$ & 0.008999 & $0.077628 * *$ & 0.012008 & $0.143395 * *$ & 0.010758 \\
\hline HHSize $=2$ & $0.026891^{* *}$ & 0.006524 & 0.006171 & 0.009285 & $0.019039 *$ & 0.007919 \\
\hline HHSize $=3$ & $0.027473 * *$ & 0.007943 & -0.00584 & 0.011018 & 0.005346 & 0.009769 \\
\hline HHSize $=4$ & $0.039426 * *$ & 0.008706 & $-0.02402^{*}$ & 0.011786 & 0.012727 & 0.010729 \\
\hline HHSize $=5+$ & $0.038727 * *$ & 0.010163 & $-0.04414^{* *}$ & 0.013609 & -0.00073 & 0.012475 \\
\hline Age $25-34$ & $0.033192 * *$ & 0.010112 & $0.032806^{*}$ & 0.014472 & $0.025512+$ & 0.01381 \\
\hline Age 35-44 & $0.035138^{* *}$ & 0.009554 & 0.010123 & 0.013695 & $-0.02399+$ & 0.013005 \\
\hline Age 45-54 & $0.053312^{* *}$ & 0.00978 & $0.045542^{* *}$ & 0.01381 & $-0.03723^{* *}$ & 0.01299 \\
\hline Age 55-64 & $0.049081 * *$ & 0.010332 & $0.03032 *$ & 0.014593 & $-0.07894 * *$ & 0.013563 \\
\hline Age 65+ & $0.055081 * *$ & 0.010441 & 0.007303 & 0.014782 & $-0.11038^{* *}$ & 0.013568 \\
\hline Constant & -0.0176373 & 0.1119977 & 0.1826995 & 0.1565165 & 0.1630899 & 0.1363424 \\
\hline $\begin{array}{c}\text { DMA-level } \\
\text { Dummies }\end{array}$ & \multicolumn{2}{|c|}{ Yes } & \multicolumn{2}{|c|}{ Yes } & \multicolumn{2}{|c|}{ Yes } \\
\hline R-squared & \multicolumn{2}{|c|}{0.073} & \multicolumn{2}{|c|}{0.075} & \multicolumn{2}{|c|}{0.115} \\
\hline Observations & \multicolumn{2}{|c|}{25668} & \multicolumn{2}{|c|}{25668} & \multicolumn{2}{|c|}{25668} \\
\hline
\end{tabular}

\footnotetext{
$34 * *$ is significant at $1 \%$ level; * is significant at $5 \%$ level; + is significant at $10 \%$ level. Reported standard errors are robust to heteroskedasticity. Results change trivially when errors are clustered by DMA.
} 
Table $3 \mathbf{a}^{35}$

2007-2008: NN by DMA, income, education, household size, and age level

\begin{tabular}{|c|c|c|c|c|c|c|}
\hline Covariates & \multicolumn{6}{|c|}{ Dependent Variable } \\
\hline & \multicolumn{2}{|c|}{ Telephone } & \multicolumn{2}{|c|}{ Television } & \multicolumn{2}{|c|}{ Broadband } \\
\hline & Coeff. & Std. Err. & Coeff. & Std. Err. & Coeff. & Std. Err. \\
\hline DepVar $_{\mathrm{t}-1}$ & $0.083544 * *$ & 0.005228 & $0.068013^{* *}$ & 0.005124 & $0.067105^{* *}$ & 0.007489 \\
\hline Bundle $_{\mathrm{t}-1}$ & -0.00159 & 0.003332 & 0.001374 & 0.004367 & 0.008327 & 0.005189 \\
\hline AllThree $_{\mathrm{t}-1}$ & 0.000666 & 0.003005 & 0.002109 & 0.00412 & -0.00672 & 0.007369 \\
\hline H.S. Degree & $0.031908 * *$ & 0.005862 & $0.043825 * *$ & 0.007678 & $0.079597 * *$ & 0.009125 \\
\hline Some College & $0.024179 * *$ & 0.005843 & $0.035226 * *$ & 0.007653 & $0.150358 * *$ & 0.009106 \\
\hline $\begin{array}{l}\text { College } \\
\text { Degree }\end{array}$ & $0.018391 * *$ & 0.006283 & $0.028118 * *$ & 0.008233 & $0.208529 * *$ & 0.009802 \\
\hline $\begin{array}{l}\text { Graduate } \\
\text { Degree }\end{array}$ & $0.019309 * *$ & 0.006777 & 0.013057 & 0.008883 & $0.225605^{* *}$ & 0.010577 \\
\hline $25 \mathrm{~K}-49 \mathrm{~K}$ & $0.016787^{* *}$ & 0.003946 & $0.087205^{* *}$ & 0.005176 & $0.123007^{* *}$ & 0.006141 \\
\hline $50 \mathrm{~K}-69 \mathrm{~K}$ & $0.029842 * *$ & 0.00451 & $0.126169 * *$ & 0.005916 & $0.210987^{* *}$ & 0.007022 \\
\hline $70 \mathrm{~K}-99 \mathrm{~K}$ & $0.041538 * *$ & 0.004808 & $0.152183^{* *}$ & 0.006308 & $0.266498^{* *}$ & 0.007485 \\
\hline $100 \mathrm{~K}+$ & $0.040387 * *$ & 0.004958 & $0.173348 * *$ & 0.006507 & $0.316723^{* *}$ & 0.00772 \\
\hline HHSize $=2$ & $0.033737 * *$ & 0.003988 & $0.058865^{* *}$ & 0.005226 & $0.077471^{* *}$ & 0.006207 \\
\hline HHSize $=3$ & $0.055674 * *$ & 0.004645 & $0.065067 * *$ & 0.006081 & $0.09272 * *$ & 0.007226 \\
\hline HHSize $=4$ & $0.071764 * *$ & 0.005031 & $0.05087 * *$ & 0.00658 & $0.116814^{* *}$ & 0.00782 \\
\hline HHSize $=5+$ & $0.063856 * *$ & 0.005706 & 0.00379 & 0.007467 & $0.105043^{* *}$ & 0.008873 \\
\hline Age 25-34 & $0.019886 * *$ & 0.005821 & $0.053746^{* *}$ & 0.007624 & $0.030638^{* *}$ & 0.009059 \\
\hline Age 35-44 & $0.123518^{* *}$ & 0.005559 & $0.064164^{* *}$ & 0.007261 & -0.0068 & 0.008641 \\
\hline Age 45-54 & $0.161678^{* *}$ & 0.005495 & $0.060612^{* *}$ & 0.007157 & $-0.04086^{* *}$ & 0.008529 \\
\hline Age 55-64 & $0.19543 * *$ & 0.0058 & $0.073015^{* *}$ & 0.00753 & $-0.07845^{* *}$ & 0.008988 \\
\hline Age 65+ & $0.229752^{* *}$ & 0.00595 & $0.050879 * *$ & 0.007681 & $-0.20071^{* *}$ & 0.0092 \\
\hline Constant & $0.5863374 * *$ & 0.041823 & $0.4739165 * *$ & 0.0546565 & $0.2486567 * *$ & 0.0648644 \\
\hline $\begin{array}{c}\text { DMA-level } \\
\text { Dummies }\end{array}$ & \multicolumn{2}{|c|}{ Yes } & \multicolumn{2}{|c|}{ Yes } & \multicolumn{2}{|c|}{ Yes } \\
\hline R-squared & \multicolumn{2}{|c|}{0.095} & \multicolumn{2}{|c|}{0.057} & \multicolumn{2}{|c|}{0.176} \\
\hline Observations & \multicolumn{2}{|c|}{47698} & \multicolumn{2}{|c|}{47698} & \multicolumn{2}{|c|}{47698} \\
\hline
\end{tabular}

\footnotetext{
$35 * *$ is significant at $1 \%$ level; * is significant at $5 \%$ level; + is significant at $10 \%$ level. Reported standard errors are robust to heteroskedasticity. Results change trivially when errors are clustered by DMA.
} 
Table $3 \mathbf{b}^{36}$

2007-2008: NN by DMA, income, education, household size, and age level

\begin{tabular}{|c|c|c|c|c|c|c|}
\hline \multirow[t]{3}{*}{ Covariates } & \multicolumn{6}{|c|}{ Dependent Variable } \\
\hline & \multicolumn{2}{|c|}{ TelephoneCableCo } & \multicolumn{2}{|c|}{ TelevisionCableCo } & \multicolumn{2}{|c|}{ BroadbandCableCo } \\
\hline & Coeff. & Std. Err. & Coeff. & Std. Err. & Coeff. & Std. Err. \\
\hline DepVar $_{\mathrm{t}-1}$ & $0.056902^{* *}$ & 0.006238 & $0.072685^{* *}$ & 0.004751 & $0.062294^{* *}$ & 0.005181 \\
\hline Bundle $_{\mathrm{t}-1}$ & 0.004778 & 0.004703 & -0.00243 & 0.005717 & $0.008903+$ & 0.005181 \\
\hline AllThree $_{\mathrm{t}-1}$ & 0.004626 & 0.003488 & $-7.3 \mathrm{E}-05$ & 0.005081 & 0.007473 & 0.004644 \\
\hline H.S. Degree & 0.008996 & 0.007049 & $0.027639 * *$ & 0.010048 & $0.030183^{* *}$ & 0.009 \\
\hline Some College & $0.013084+$ & 0.007025 & $0.034608^{* *}$ & 0.010014 & $0.064097 * *$ & 0.008972 \\
\hline $\begin{array}{l}\text { College } \\
\text { Degree }\end{array}$ & $0.014915^{*}$ & 0.007554 & $0.062243 * *$ & 0.010768 & $0.089904^{* *}$ & 0.009648 \\
\hline $\begin{array}{l}\text { Graduate } \\
\text { Degree }\end{array}$ & -0.00118 & 0.008149 & $0.060632 * *$ & 0.011614 & $0.093796^{* *}$ & 0.010408 \\
\hline $25 \mathrm{~K}-49 \mathrm{~K}$ & $0.011371^{*}$ & 0.004744 & $0.029566 * *$ & 0.006762 & $0.055886^{* *}$ & 0.006057 \\
\hline $50 \mathrm{~K}-69 \mathrm{~K}$ & $0.02401^{* *}$ & 0.005422 & $0.04889 * *$ & 0.007728 & $0.10264 * *$ & 0.006923 \\
\hline $70 \mathrm{~K}-99 \mathrm{~K}$ & $0.038195^{* *}$ & 0.00578 & $0.072475^{* *}$ & 0.008238 & $0.136438^{* *}$ & 0.007381 \\
\hline $100 \mathrm{~K}+$ & $0.040405^{* *}$ & 0.005962 & $0.094946^{* *}$ & 0.008498 & $0.171336^{* *}$ & 0.007619 \\
\hline HHSize $=2$ & $0.02234 * *$ & 0.004795 & -0.00482 & 0.006837 & $0.034358^{* *}$ & 0.006123 \\
\hline HHSize $=3$ & $0.035454 * *$ & 0.005583 & 0.000495 & 0.007963 & $0.045787^{* *}$ & 0.007128 \\
\hline HHSize $=4$ & $0.041476^{* *}$ & 0.006041 & $-0.0253 * *$ & 0.008621 & $0.048786^{* *}$ & 0.007714 \\
\hline HHSize $=5+$ & $0.042779 * *$ & 0.006854 & $-0.04922 * *$ & 0.009782 & $0.045882^{* *}$ & 0.008751 \\
\hline Age 25-34 & $0.013073+$ & 0.006999 & $-0.02178^{*}$ & 0.009977 & 0.000522 & 0.008937 \\
\hline Age 35-44 & $0.020276^{* *}$ & 0.006665 & $-0.01833+$ & 0.009502 & $-0.04108^{* *}$ & 0.00851 \\
\hline Age 45-54 & $0.020604^{* *}$ & 0.006569 & -0.00065 & 0.009364 & $-0.05628 * *$ & 0.00839 \\
\hline Age 55-64 & $0.026865^{* *}$ & 0.006911 & 0.002004 & 0.009852 & $-0.07654^{* *}$ & 0.00883 \\
\hline Age 65+ & $0.012261+$ & 0.00705 & 0.001599 & 0.010049 & $-0.12353^{* *}$ & 0.009013 \\
\hline Constant & 0.0160156 & 0.0501062 & $0.3075835^{* *}$ & 0.0714284 & $0.1516641 *$ & 0.063978 \\
\hline $\begin{array}{c}\text { DMA-level } \\
\text { Dummies }\end{array}$ & \multicolumn{2}{|c|}{ Yes } & \multicolumn{2}{|c|}{ Yes } & \multicolumn{2}{|c|}{ Yes } \\
\hline R-squared & \multicolumn{2}{|c|}{0.047} & \multicolumn{2}{|c|}{0.054} & \multicolumn{2}{|c|}{0.083} \\
\hline Observations & \multicolumn{2}{|c|}{47698} & \multicolumn{2}{|c|}{47698} & \multicolumn{2}{|c|}{47698} \\
\hline
\end{tabular}

\footnotetext{
$36 * *$ is significant at $1 \%$ level; * is significant at $5 \%$ level; + is significant at $10 \%$ level. Reported standard errors are robust to heteroskedasticity. Results change trivially when errors are clustered by DMA.
} 
Table $3 c^{\underline{37}}$

2008-2009: NN by DMA, income, education, household size, and age level

\begin{tabular}{|c|c|c|c|c|c|c|}
\hline Covariates & \multicolumn{6}{|c|}{ Dependent Variable } \\
\hline & \multicolumn{2}{|c|}{ Telephone } & \multicolumn{2}{|c|}{ Television } & \multicolumn{2}{|c|}{ Broadband } \\
\hline & Coeff. & Std. Err. & Coeff. & Std. Err. & Coeff. & Std. Err. \\
\hline DepVar $_{\mathrm{t}-1}$ & $0.117952^{* *}$ & 0.006447 & $0.087545^{* *}$ & 0.006561 & $0.094963^{* *}$ & 0.007817 \\
\hline Bundle $_{\mathrm{t}-1}$ & 0.001478 & 0.004201 & 0.006919 & 0.005178 & 0.002114 & 0.005292 \\
\hline AllThree $_{\mathrm{t}-1}$ & -0.00239 & 0.004247 & 0.008331 & 0.005361 & -0.0065 & 0.007475 \\
\hline H.S. Degree & 0.011193 & 0.007945 & $0.047568 * *$ & 0.009744 & $0.127397 * *$ & 0.010009 \\
\hline Some College & -0.00215 & 0.007937 & $0.059664 * *$ & 0.009737 & $0.242401^{* *}$ & 0.010011 \\
\hline $\begin{array}{l}\text { College } \\
\text { Degree }\end{array}$ & -0.01219 & 0.008492 & $0.047868 * *$ & 0.010417 & $0.303912^{* *}$ & 0.010729 \\
\hline $\begin{array}{l}\text { Graduate } \\
\text { Degree }\end{array}$ & -0.00705 & 0.0091 & $0.034008^{* *}$ & 0.011167 & $0.30956 * *$ & 0.011501 \\
\hline $25 \mathrm{~K}-49 \mathrm{~K}$ & $0.015417^{* *}$ & 0.005385 & $0.095959 * *$ & 0.006608 & $0.12044 * *$ & 0.006792 \\
\hline $50 \mathrm{~K}-69 \mathrm{~K}$ & $0.037308^{* *}$ & 0.006203 & $0.134826^{* *}$ & 0.007613 & $0.177358^{* *}$ & 0.00783 \\
\hline $70 \mathrm{~K}-99 \mathrm{~K}$ & $0.046041^{* *}$ & 0.006359 & $0.167109 * *$ & 0.007805 & $0.218399 * *$ & 0.008034 \\
\hline $100 \mathrm{~K}+$ & $0.056643 * *$ & 0.006511 & $0.186777^{* *}$ & 0.007992 & $0.263231^{* *}$ & 0.008224 \\
\hline HHSize $=2$ & $0.038351^{* *}$ & 0.00548 & $0.062549 * *$ & 0.00672 & $0.059941^{* *}$ & 0.006901 \\
\hline HHSize $=3$ & $0.060096^{* *}$ & 0.006217 & $0.057466 * *$ & 0.00762 & $0.054285^{* *}$ & 0.007827 \\
\hline HHSize $=4$ & $0.080563 * *$ & 0.006594 & $0.051832 * *$ & 0.008079 & $0.074332 * *$ & 0.008298 \\
\hline HHSize $=5+$ & $0.07592 * *$ & 0.007277 & 0.0199* & 0.008924 & $0.064036^{* *}$ & 0.009163 \\
\hline Age 25-34 & $0.022818^{* *}$ & 0.007337 & $0.089127^{* *}$ & 0.008999 & $0.025089 * *$ & 0.009242 \\
\hline Age 35-44 & $0.163164^{* *}$ & 0.007058 & $0.087493^{* *}$ & 0.008622 & -0.00345 & 0.008867 \\
\hline Age 45-54 & $0.212004^{* *}$ & 0.007121 & $0.093981^{* *}$ & 0.008664 & $-0.05409 * *$ & 0.008924 \\
\hline Age 55-64 & $0.245225^{* *}$ & 0.00756 & $0.111023^{* *}$ & 0.009167 & $-0.10058^{* *}$ & 0.009462 \\
\hline Age 65+ & $0.290423^{* *}$ & 0.007803 & $0.076278^{* *}$ & 0.009394 & $-0.21166^{* *}$ & 0.009739 \\
\hline Constant & $0.2860116^{* *}$ & 0.0698106 & $0.4750731^{* *}$ & 0.0855205 & $0.2318432^{* *}$ & 0.0877831 \\
\hline $\begin{array}{c}\text { DMA-level } \\
\text { Dummies }\end{array}$ & \multicolumn{2}{|c|}{ Yes } & \multicolumn{2}{|c|}{ Yes } & \multicolumn{2}{|c|}{ Yes } \\
\hline R-squared & \multicolumn{2}{|c|}{0.123} & \multicolumn{2}{|c|}{0.066} & \multicolumn{2}{|c|}{0.209} \\
\hline Observations & \multicolumn{2}{|c|}{36194} & \multicolumn{2}{|c|}{36194} & \multicolumn{2}{|c|}{36194} \\
\hline
\end{tabular}

$37 * *$ is significant at $1 \%$ level; * is significant at $5 \%$ level; + is significant at $10 \%$ level. Reported standard errors are robust to heteroskedasticity. Results change trivially when errors are clustered by DMA. 
Table 3d ${ }^{38}$

2008-2009: NN by DMA, income, education, household size, and age level

\begin{tabular}{|c|c|c|c|c|c|c|}
\hline \multirow[t]{3}{*}{ Covariates } & \multicolumn{6}{|c|}{ Dependent Variable } \\
\hline & \multicolumn{2}{|c|}{ TelephoneCableCo } & \multicolumn{2}{|c|}{ TelevisionCableCo } & \multicolumn{2}{|c|}{ BroadbandCableCo } \\
\hline & Coeff. & Std. Err. & Coeff. & Std. Err. & Coeff. & Std. Err. \\
\hline DepVar $_{\mathrm{t}-1}$ & $0.084987^{* *}$ & 0.006466 & $0.087571^{* *}$ & 0.005424 & $0.086076^{* *}$ & 0.005726 \\
\hline Bundle $_{\mathrm{t}-1}$ & $0.01531 * *$ & 0.005231 & 0.009568 & 0.006187 & 0.005879 & 0.005818 \\
\hline AllThree $_{\mathrm{t}-1}$ & -0.00023 & 0.004363 & 0.003065 & 0.005935 & 0.002774 & 0.005461 \\
\hline H.S. Degree & 0.007017 & 0.008678 & $0.040342 * *$ & 0.011628 & $0.044505^{* *}$ & 0.01066 \\
\hline Some College & 0.011442 & 0.00867 & $0.055949 * *$ & 0.011618 & $0.090605^{* *}$ & 0.010651 \\
\hline $\begin{array}{l}\text { College } \\
\text { Degree }\end{array}$ & 0.003739 & 0.009275 & $0.079965^{* *}$ & 0.012427 & $0.139486 * *$ & 0.011395 \\
\hline $\begin{array}{l}\text { Graduate } \\
\text { Degree }\end{array}$ & 0.000692 & 0.009941 & $0.077806^{* *}$ & 0.013318 & $0.143072 * *$ & 0.012212 \\
\hline $25 \mathrm{~K}-49 \mathrm{~K}$ & $0.013042 *$ & 0.005881 & $0.037359 * *$ & 0.00788 & $0.051908^{* *}$ & 0.007226 \\
\hline $50 \mathrm{~K}-69 \mathrm{~K}$ & $0.021302 * *$ & 0.006774 & $0.0624 * *$ & 0.009078 & $0.085478 * *$ & 0.008327 \\
\hline $70 \mathrm{~K}-99 \mathrm{~K}$ & $0.046252 * *$ & 0.006946 & $0.083131 * *$ & 0.009306 & $0.122573^{* *}$ & 0.008539 \\
\hline $100 \mathrm{~K}+$ & $0.043917^{* *}$ & 0.007112 & $0.104413^{* *}$ & 0.009529 & $0.155758^{* *}$ & 0.008746 \\
\hline HHSize $=2$ & $0.030181^{* *}$ & 0.005983 & -0.00113 & 0.00802 & $0.023205^{* *}$ & 0.00735 \\
\hline HHSize $=3$ & $0.032889 * *$ & 0.006785 & -0.00997 & 0.009096 & $0.016568 *$ & 0.008336 \\
\hline HHSize $=4$ & $0.047734 * *$ & 0.007194 & $-0.03748 * *$ & 0.00965 & 0.012493 & 0.008838 \\
\hline HHSize $=5+$ & $0.045801^{* *}$ & 0.007942 & $-0.03999 * *$ & 0.010657 & 0.008841 & 0.009758 \\
\hline Age 25-34 & $0.033392 * *$ & 0.008013 & 0.014325 & 0.010738 & $0.018587+$ & 0.009843 \\
\hline Age $35-44$ & $0.04224 * *$ & 0.007677 & -0.01223 & 0.010289 & $-0.03564^{* *}$ & 0.009434 \\
\hline Age 45-54 & $0.057178^{* *}$ & 0.007715 & $0.027805^{* *}$ & 0.010339 & $-0.05216^{* *}$ & 0.009484 \\
\hline Age 55-64 & $0.05465 * *$ & 0.008161 & $0.022243^{*}$ & 0.010936 & $-0.08914^{* *}$ & 0.010036 \\
\hline Age 65+ & $0.058202 * *$ & 0.008362 & -0.0045 & 0.011206 & $-0.1308 * *$ & 0.010289 \\
\hline Constant & -0.0345563 & 0.0761003 & $0.2861494 * *$ & 0.1019951 & 0.1453506 & 0.0934899 \\
\hline $\begin{array}{c}\text { DMA-level } \\
\text { Dummies }\end{array}$ & \multicolumn{2}{|c|}{ Yes } & \multicolumn{2}{|c|}{ Yes } & \multicolumn{2}{|c|}{ Yes } \\
\hline R-squared & \multicolumn{2}{|c|}{0.057} & \multicolumn{2}{|c|}{0.058} & \multicolumn{2}{|c|}{0.097} \\
\hline Observations & \multicolumn{2}{|c|}{36194} & \multicolumn{2}{|c|}{36194} & \multicolumn{2}{|c|}{36194} \\
\hline
\end{tabular}

\footnotetext{
38 ** is significant at $1 \%$ level; * is significant at $5 \%$ level; + is significant at $10 \%$ level. Reported standard errors are robust to heteroskedasticity. Results change trivially when errors are clustered by DMA.
} 